NBER WORKING PAPER SERIES

\title{
DISTORTION BY AUDIT: EVIDENCE FROM PUBLIC PROCUREMENT
}

\author{
Maria Paula Gerardino \\ Stephan Litschig \\ Dina Pomeranz \\ Working Paper 23978 \\ http://www.nber.org/papers/w23978 \\ NATIONAL BUREAU OF ECONOMIC RESEARCH \\ 1050 Massachusetts Avenue \\ Cambridge, MA 02138 \\ October 2017, Revised August 2022
}

\begin{abstract}
We thank Alberto Abadie, Yoichi Arai, Oriana Bandiera, Abhijit Banerjee, Michael Best, Lorenzo Casaburi, David Cutler, Rafael Di Tella, David Dorn, Eduardo Engel, Ben Faber, Andres Gonzalez Lira, Caroline Hoxby, Seema Jayachandran, Lawrence Katz, Adnan Khan, Asim Khwaja, Gary King, Jon Kolstad, Wojciech Kopczuk, Juliana Londoño Vélez, Michel Maréchal, Stephan Meier, Luke Miller, Mushfiq Mobarak, Francisco Nahmias Joana Naritomi, Paul Novosad, Rohini Pande, Zhuan Pei, Marek Pycia, Nancy Qian, Debraj Ray, Giancarlo Spagnolo, Stéphane Straub, Juan Carlos Suarez, Dimitri Szerman, Roberto Weber, Jonathan Weigel, Danny Yagan, David Yanagizawa-Drott, Lucas Zavala and participants at the NBER and CEPR public economics meetings, BREAD, LACEA, RIDGE and numerous seminars for helpful comments and discussions. Particular thanks go to Ben Olken for extensive conversations on the design of the special audits. We are grateful to the public procurement agency ChileCompra and the national comptroller Contraloría General de la República for excellent collaboration, to the Spanish Ministry of Economy and Competitiveness for generous support through the Severo Ochoa Programme for Centres of Excellence in R\&D, and to the Development Bank of Latin America and the Abdul Latif Jameel Poverty Action Lab's Governance Initiative for support. The views expressed herein are those of the authors and do not necessarily reflect the views of the National Bureau of Economic Research.
\end{abstract}

NBER working papers are circulated for discussion and comment purposes. They have not been peer-reviewed or been subject to the review by the NBER Board of Directors that accompanies official NBER publications.

(C) 2017 by Maria Paula Gerardino, Stephan Litschig, and Dina Pomeranz. All rights reserved. Short sections of text, not to exceed two paragraphs, may be quoted without explicit permission provided that full credit, including $(\odot$ notice, is given to the source. 
Distortion by Audit: Evidence from Public Procurement

Maria Paula Gerardino, Stephan Litschig, and Dina Pomeranz

NBER Working Paper No. 23978

October 2017, Revised August 2022

JEL No. D73,H57,O38

\begin{abstract}
$\underline{\text { ABSTRACT }}$ unintended distortions. Regression discontinuity analysis from Chile shows that audits lowered likelihood of incumbent, small, and local firms winning contracts. Looking inside the black box of the audit process reveals that relative to comparable direct contracts, auctions underwent more than twice as many checks and led to twice as many detected infractions. Procurement officers standard audit protocols can mechanically discourage the use of more regulated, complex and transparent procedures that involve more auditable steps.

Maria Paula Gerardino

Inter-American Development Bank

1300 New York Avenue NW

Washington, DC 20577

mariage@iadb.org

Stephan Litschig

National Graduate Institute for Policy Studies

7-22-1 Roppongi, Minato-ku

Tokyo 106-8677

Japan

s-litschig@grips.ac.jp

Dina Pomeranz

Department of Economics

University of Zurich

Schoenberggasse 1

8057 Zurich

Switzerland

dina.pomeranz@econ.uzh.ch
\end{abstract}

Public sector audits are a key element of state capacity. However, we find that they can create the use of auctions for public procurement, reduced supplier competition, and increased the perceive the consequences of such detected infractions as severe. These findings show that

A Data Appendix is available at https://www.nber.org/data-appendix/w23978 


\section{Introduction}

No state can successfully execute its functions, ranging from infrastructure provision to regulation and redistribution, without a reliable way of monitoring rule compliance through audits. While the economics literature usually considers audits as neutral information collection tools (e.g. Becker, 1968), we show that they can create (unintended) distortions. In particular, looking into the black box of the audit process reveals that commonly used mechanical "auditing by checklist" approaches may inadvertently discourage the use of more regulated, complex and transparent procedures and ultimately reduce the transparency and competitiveness of the process that audits were designed to improve.

We empirically analyze this issue in public procurement: an important but understudied area of public finance and a key focus of government auditing. We present four main empirical findings. First, using regression discontinuity analysis, we find that audits trigger a subsequent shift away from transparent auctions towards less competitive direct contracting. This distortion goes against the goals of the national public procurement regulation the audits are intended to enforce. Second, this leads to a significant reduction in supplier competition and, consistent with a process that favors insiders, subsequent contracts are more likely to be awarded to incumbent, small, and local firms. We also find suggestive evidence of a price increase. Third, we collect additional data on the audit process itself and find that relative to comparable direct contracts, auctions mechanically undergo more than twice as many checks and lead to twice as many detected infractions and follow-up investigations. Fourth, a novel survey on procurement officer beliefs shows that while formal sanctions for detected infractions are perceived to be relatively rare, other consequences, including career concerns, social-image concerns and self-image concerns, are frequent, and officers perceive overall consequences as severe. Overall, these results suggest that the audit design distorted procurement officers' incentives against the use of auctions in public procurement.

Such distortions can have important impacts, given the large role public procurement plays in many markets. Public procurement includes most public spending other than salaries and transfers and represents a large share of the economy (about 13\% of GDP and 29\% of total general government expenditures in the OECD (OECD, 2016a)). The government is the largest buyer in most countries, and public procurement contracts can have significant 
impacts on supplier firms (e.g. Ferraz et al., 2021; Carrillo et al., 2022; Hjort et al., 2021; Barrot and Nanda, 2020). Free and fair competition for government contracts is therefore of great importance not only for the quality and cost of government purchases, but also to create a level playing field for all firms. In contrast to private sector procurement, where firms are free to choose their suppliers as they wish, governments have an obligation to provide equal access and not to discriminate in their choice of suppliers. Privileging incumbents and connected firms creates barriers to entry for new firms, with potential detrimental effects on innovation and economic growth. For these reasons, many governments and international organizations promote the use of competitive and transparent public auctions over direct contracting procedures (e.g. OECD, 2015; World Bank, 2016).

Measuring impacts of audits on subsequent behavior is notoriously difficult since entities selected for an audit are usually different from others in many observable and unobservable ways. To overcome this challenge, we exploit cutoffs in the audit selection process of the Chilean Comptroller Agency. This allows us to employ a fuzzy regression discontinuity design (RDD) using administrative data on the universe of public purchases in the country in 2011-2012. We compare the procurement behavior of public entities just above and below the cutoffs above which a higher proportion of entities was audited.

Our analysis reveals that audits led to a strong reduction in the use of auctions and a corresponding increase in direct contracting as the contract awarding procedure. The shift surprised the leadership of the Chilean Comptroller Agency, since prior to the study period, the government had started to increasingly promote the use of auctions and discourage the overuse of direct contracting, both through regulatory changes (Chile Compra, 2009, 2010a,c, 2016) and trainings for procurement officers (Chile Compra, 2010b). Comptrollers assumed that, if anything, audits would induce entities to increase the use of auctions. They were especially concerned about the finding that more than half of the shift towards direct contracting was justified as "emergency", the justification known to be most prone to overuse. $^{1}$

Next, we analyze whether the shift has real impacts. We find a significant reduction in competition: There is a strong move away from auctions with more than three bidders and

\footnotetext{
${ }^{1}$ This is the case not only in Chile but also in other settings, e.g. Robinson and Weigel (2018).
} 
towards direct contracts that only require one quote. This has implications for the type of firms that win the contracts: More contracts are awarded to incumbents that have sold to the same entity before, as well as to small and local firms. At the same time, there is no impact on total spending or on product choice. Finally, we also find a substantial increase in prices within the subset of products for which we can compare prices and for which there is a sizeable shift towards direct contracts.

To study the mechanism underlying the shift away from auctions, we worked with the Comptroller Agency to collect data on the content of the audit itself. ${ }^{2}$ These data revealed that, relative to comparable direct contracts, auctions undergo more than twice as many checks, lead to twice as many detected infractions, and are twice as likely to trigger formal follow-up investigations. This stems mechanically from the fact that audit protocols typically include many more checks for auctions than for direct contracts, not only in Chile, but in many jurisdictions. ${ }^{3}$ If agents run the risk of making a mistake in any given step of the process, procedures involving more steps, and correspondingly more checks, will mechanically lead to a higher probability of being found incompliant. When procurement officers learn that, despite the recent push for auctions by the government, using auctions leads to more problems during audits, this incentivizes them to use more direct contracting instead.

It is, of course, possible that contracts for which auctions and direct contracting are used differ along observable or unobservable dimensions. We deal with this in two ways. First, we show that the differences in number of checks and detected infractions remain very similar when controlling for contract characteristics such as purchase amount and type of product. Second, we find that most of these differences stem from the awarding stage, where the process differs most between procurement procedures, rather than from the execution stage, which is very similar irrespective of procedure.

\footnotetext{
${ }^{2}$ This type of analysis was not possible previously, as typical audit reports only include detected infractions, not information on the audit process at the level of individual purchases. To overcome this data limitation, the Comptroller agreed to conduct additional audits to gather such information.

${ }^{3}$ In Chile, the number of potential checks focusing especially on auctions is 53, whereas it is 4-7 for direct contracts, depending on the size of the purchase. See Online Appendix B for the Chilean audit protocol. For the U.S. federal government, see e.g. Office of Management and Budget (2018) and Governmental Auditing Standards and Title 2 U.S. Code of Federal Regulations (2020). For U.S. state governments, see e.g. Minnesota Auditor General Office (2018), Arizona Auditor General Office (2020). For the EU see e.g. The Contact Committee of the Supreme Audit Institutions of the European Union (2018). For other countries, see e.g. Secretaría de la Función Pública de Mexico (2009) or Sri Lanka Auditor General's Department (2016).
} 
To shed light on the consequences of detected infractions, we implemented a countrywide online survey among procurement officers from entities with recent audit experience. While much of the analysis of deterrence from audits-building on the seminal model of crime by Becker (1968) - has focused on legal consequences of detected infractions, such as prosecutions and penalties, we document that additional consequences can play an important role, including career concerns, social-image concerns and self-image concerns. Even though the risks of purely legal penalties are relatively low, $73 \%$ of officers perceive the overall consequences as equally or more severe than having a $5 \%$ lower income in the following year.

The survey evidence also helps to investigate - in combination with administrative data - two alternative mechanisms. First, entities might increase the use of direct contracts in year $t$ because the likelihood of another audit in year $t+1$ might be low, and contracts awarded in year $t$ might therefore be less subject to scrutiny. Analysis of actual re-audit probabilities shows that this is not the case and the survey confirms that the vast majority of procurement officers is aware that contracts made during the year of an audit are not less likely to be audited subsequently. Second, the audits might increase the workload of procurement officers to the point that they fall behind and run into true emergencies. However, the survey shows that, in our context, being audited is only minimally disruptive.

The new distortionary mechanism we identify in this paper is both simple and very general. It can apply in any setting - in the public or private sector-where audits are designed to maximize the detection of infractions but agents have some discretion over the choice of procedure. This is typically the case in public procurement (see e.g. Spagnolo, 2012; Palguta and Pertold, 2017). While governments tend to promote more transparent and competitive procedures over direct contracts, exceptions are usually allowed for cases where auctions are impractical or inefficient, such as in emergencies or when only one supplier is available. This leads to some discretion inherent in the choice of procurement procedure.

More generally, our results show that the widespread mechanical auditing approach that we call "auditing by checklist" can inadvertently discourage the use of more regulated, complex and transparent procedures that tend to involve more steps and leave a longer paper trail. ${ }^{4}$ This distortion can undermine underlying policy goals, unless the regulator actually

\footnotetext{
${ }^{4}$ Of course, not all mechanical auditing rules lead to distortions, and checklist approaches could in principle
} 
intends to discourage exactly such procedures. In many cases, however, the reverse is true. This has important implications for monitoring agencies aiming to design audit processes that keep incentives neutral across procedures. If agencies optimize audit design without taking agents' discretion into account, this can lead to unintended distortions. We provide a simple conceptual framework to illustrate this mechanism and discuss potential ways to address it through differential penalties and audit probabilities.

This paper contributes to multiple strands of the literature. First, it extends past work on audits by demonstrating how international best practices can unintentionally reduce the use of competitive auctions in public procurement. Existing work finds that public sector audits reduce corruption (Avis et al., 2018), improve firm performance (Colonnelli and Prem, 2022), and increase electoral accountability (Ferraz and Finan, 2008). Similarly, an increase in audit risk has been shown to curb corruption in road construction (Olken, 2007) and public procurement (Zamboni and Litschig, 2018). ${ }^{5}$ Scholars have also noted limits to effective auditing, such as inefficient targeting (e.g. Duflo et al., 2018), predictable timing (GonzalezLira and Mobarak, 2019), substitution of illicit behavior to other less measurable margins (e.g. Yang, 2008; Niehaus and Sukhtankar, 2013; Carrillo et al., 2017; Lichand and Fernandes, 2019), and the integrity and effort of auditors themselves (e.g. Kahn et al., 2001; Khan et al., 2016; Chu et al., 2020; Bandiera et al., 2021). ${ }^{6}$ This paper furthers this literature by showing that audits can not only be ineffective but can actually backfire by creating unintended distortions even in a low-corruption, high-capacity setting. It identifies a very general mechanism through which audits can undermine the very processes they are meant to improve. This is also the first paper we know of to analyze the role of the audit protocol in shaping the incentives and choices of bureaucrats under scrutiny.

Second, our paper contributes to the literature on public procurement by analyzing the role of audits in the choice of purchase procurement procedure. A growing literature

take such distortions into account, e.g. by adjusting penalties or audit probabilities, as we discuss below.

${ }^{5}$ In the case of taxes, Kleven et al. (2011), DeBacker et al. (2015), DeBacker et al. (2018) and Advani et al. (2021) analyze the impacts of audits of individuals in Denmark and the U.K, and of firms and individuals in the US, respectively. Kleven et al. (2011) and Pomeranz (2015) study the effects of audit risk. See Pomeranz and Vila-Belda (2019) for an overview of recent research with tax authorities.

${ }^{6}$ In the case of government mandated, privately provided audits, limited effectiveness has been found to result from collusion (e.g. Duflo et al., 2013a,b). 
empirically analyzes the impacts of different procurement procedures. ${ }^{7}$ Several studies find improved outcomes under auctions compared to direct contracts in terms of lower prices and higher quality (Lalive et al., 2015), lower prices and more productive suppliers (Szucs, 2020), and more productive and less politically connected contractors (Baltrunaite et al., 2021). ${ }^{8}$ At the same time, a recent set of papers investigates the trade-offs between rules and discretion in public procurement and find that higher levels of discretion can lead to improved procurement outcomes in terms of both costs and quality, particularly in high state capacity settings (e.g. Coviello et al., 2018; Bosio et al., 2022; Decarolis et al., 2020c; Carril, 2021; Coviello et al., 2021). ${ }^{9}$ This paper steps back and considers bureaucrats' incentives to choose auction-based procurement in the first place. Our findings reveal that the choice between different procurement procedures can be distorted by a widely used auditing practice.

To the best of our knowledge, this is also the first paper on public sector governance to provide evidence on bureaucrats' beliefs about audit probabilities and consequences for detected infractions. Our finding that consequences other than legal sanctions play an important role is in line with, e.g., Benabou and Tirole (2011), who stress the importance of intrinsic motivation and social image concerns in addition to outright legal sanctions or penalties. ${ }^{10}$ More broadly, the finding that audits discouraged certain procedures by inadvertently subjecting them to disproportionate scrutiny highlights that optimal design of organizations is perhaps a poor description of how large institutions operate in practice (e.g. Simon, 1972). This seems to be the case even in a high-capacity, low corruption environment such as Chile. ${ }^{11}$ For optimal audit design, organizations should take incentives across all margins of behavior into account (e.g. Stigler, 1970).

\footnotetext{
${ }^{7}$ For an overview of the theoretical literature see e.g. (Coviello et al., 2018).

${ }^{8}$ Similarly, comparing procedures with varying degrees of competition, Auriol et al. (2016) and Zamboni and Litschig (2018) document that more open procedures are less likely to involve corruption.

${ }^{9}$ Relatedly, a number of studies find that access to information can improve procurement outcomes such as increased entry, lower costs, better quality or shorter contracting times (e.g. Coviello and Mariniello, 2014; Lewis-Faupel et al., 2016; Kovalchuk et al., 2019). Another related literature looks at the role of bureaucrats in public procurement management, finding that passive waste can play a more important role than active rent taking (Bandiera et al., 2009) and that higher bureaucratic competence can improve procurement outcomes (Decarolis et al., 2020b). Finally, a number of papers, such as Tran (2011), Decarolis (2014), Banerjee et al. (2019) and Decarolis et al. (2020a) investigate how auction design affects efficiency in public procurement.

${ }^{10}$ See also Bursztyn and Jensen (2017) for an overview on the role of social image concerns.

${ }^{11}$ In our study period, Transparency International ranked Chile as the 20th least corrupt out of 176 countries. For comparison, the US ranked 19th (Transparency International, 2012).
} 


\section{Background}

\subsection{Public Procurement}

Procurement regulations typically include two main procedures to award contracts: direct contracting and public auctions. Under direct contracting, entities make purchases directly from suppliers they select. In auctions, purchasing entities need to specify the selection criteria explicitly in advance and any qualified firm can participate. Auctions have a built-in control mechanism, in that losers have a vested interest in checking whether the process was executed fairly and correctly. If they suspect irregularities, they can launch a complaint. For all these reasons, public auctions are considered to be conducive to transparency and competitiveness and are often recommended over single-source procurement methods (e.g. OECD, 2015; World Bank, 2016).

However, not all purchases lend themselves to auctions. In certain circumstances, conducting an auction can be inappropriate or inefficient (Bajari et al., 2009). Regulations therefore typically allow for exceptions under which auctions are not required and direct contracting is allowed. This can be the case if there is only a single supplier in the market for a particular product; if there is an emergency and the time it would take to organize an auction would lead to bigger problems; if the amount involved is small compared to the cost of organizing an auction, etc. While procurement officers need to indicate the justification for using direct contracting instead of auctions, there is some discretion inherent in the choice of procedure.

Many countries have a third procurement procedure, so-called framework agreements. These are typically managed by a central agency which runs auctions or negotiates conditions for products that are used by many entities, such as office materials. Individual public entities can then simply order products from a list of options. Framework agreements are typically also considered a competitive procurement procedure, so when a product is available in a framework agreement, the entity does not need to organize an auction.

The Chilean Context: Chile Compra (henceforth "Procurement Agency") manages the public procurement system and the online platform on which most public procurement takes 
place. The platform serves practically all public entities in Chile ${ }^{12}$ with about 1,350 entities making purchases and over 100,000 firms supplying goods and services each year (Chile Compra, 2012). During our study period, purchases on the platform represented about $3.1 \%$ of GDP (Chile Compra, 2018). Prior to our study period, the Procurement Agency started to increasingly promote the use of auctions and discourage the overuse of direct contracting, through both regulatory changes (Chile Compra, 2009, 2010c,a, 2016) and trainings for procurement officers (Chile Compra, 2010b). While historically, most purchases used to be made through direct contracting, these efforts succeeded in motivating entities to conduct a large share of purchases through auctions, mirroring similar efforts in many other countries (see e.g. OECD, 2016b). During our study period, auctions represent the largest share of purchases, followed by direct contracts and framework agreement purchases.

Auctions are conducted on the online platform, where all information about the process and specifications is publicly available. Once an auction is finalized, bids of all competing firms are also published. Chile uses so-called "scoring-auctions" in which points are given depending on a number of characteristics such as price, specific quality dimensions, experience of the supplier, qualification of their staff, etc. At least two characteristics need to be specified such that points are not only given based on price. For direct contracting, the regulation stipulates 21 possible justifications. They include cases where only one supplier exists, emergency, trust in a particular supplier, situations in which organizing an auction would represent a disproportionate cost, or purchases below about 750 USD. ${ }^{13}$ Depending on the justification, officers are required to get one or three quotes from suppliers. About $80 \%$ of direct contracts require one quote and about $20 \%$ require three. The awarding process for direct contracts is offline and information about the purchase is subsequently uploaded to the platform. When a product is available through a framework agreement, entities are required to use this option, unless they can obtain better terms through another procedure. Products that are available through framework agreement but are purchased through other procedures therefore make up a very small share of total purchases. Finally, for small purchases below about 225 USD, the use of the electronic procurement system is not required.

\footnotetext{
${ }^{12}$ There are a few exemptions such as for the armed forces. Large public works such as construction highways are not part of the online procurement system and are handled by a different agency.

${ }^{13}$ The specific threshold is 10 UTM (Unidad Tributaria Mensual, an inflation-adjusted Chilean unit of account). See our online data documentation appendix for the full list of justifications.
} 


\subsection{Audits}

Public Sector Audits: Supreme audit institutions or comptroller agencies ${ }^{14}$ are in charge of monitoring public entities and state-owned enterprises. They play an important role for state capacity by enhancing public sector transparency, performance and accountability and ensuring correct execution of regulation (e.g. INTOSAI, 2010; OECD, 2014). One of their primary monitoring activities consists of implementing audits (INTOSAI, 2010), typically including a strong focus on procurement. Auditors from the comptroller agency usually visit the public entity being audited and work behind closed doors to examine documents.

Auditors often follow a checklist to investigate whether processes were executed in accordance with the regulation (e.g. The Contact Committee of the Supreme Audit Institutions of the European Union, 2018). In the case of public procurement, common checks include the choice of purchase procedure, correct implementation of awarding criteria, supplier selection and contract execution. Following the audit, many comptroller agencies issue a preliminary report and entities can file a response explaining how the infractions occurred and what they will do to remedy the issue. Taking the entity's response into account, the comptroller releases an official final report, which in many countries is publicly available.

The Chilean Context: Contraloría is the Chilean national comptroller agency (henceforth "Comptroller"). Compared to other countries, it is particularly well-functioning and wellfunded (Engel et al., 2017). ${ }^{15}$ The timeline is as follows. At the end of each year $t-1$, the Comptroller determines which entities will be audited in year $t$. At the beginning of year $t$, selected entities are notified that they will be audited and told which documents they need to prepare. At this point, entities start getting a sense of what aspects of the procurement will be under scrutiny. Most audits begin early in the year, almost half in the first quarter. Audits usually examine completed contracts from year $t-3$ to year $t-1$. The impacts we measure are those on new purchases made in year $t$, which are not subject to the audit.

\footnotetext{
${ }^{14}$ These are known in different countries as "National Comptroller", "Auditing Agency", "Court of Auditors" or "General Accountability Office".

${ }^{15}$ Figure A1 illustrates the relationship between Procurement Agency, Comptroller, and public entities which make procurements (e.g. hospitals, schools, ministries). The Public Procurement Agency "ChileCompra" regulates the procurement process and provides the online platform. The Comptroller Agency "Contraloría" implements audits and other monitoring functions of all public entities. Public procurement is implemented by entities from small schools or hospitals to entire ministries.
} 
Audits last 2 months on average. Following standard procedure, contact between auditors and entity staff is kept at a minimum and no social interactions are allowed. Upon receipt of a preliminary report, entities learn in more detail what the auditors focused on. In the following weeks, entities prepare a response to the interim report. Based on this response, the Comptroller releases a final report publicly on the internet. In severe cases, the Comptroller can initiate a formal investigation. This serious step can involve disciplinary proceedings, restitutions for improper payments, referral to the Court of Auditors to initiate a quasi-judicial examination, or referrals for legal prosecution to the Public Prosecutor.

During the preparation of the response to the Comptroller, procurement officers who committed the infractions are typically required to explain themselves internally to their superiors. In our qualitative interviews, officials described this as a painful experience that can severely affect their career prospects. Through our country-wide procurement officer survey, we investigate the nature and severity of such consequences for the responsible procurement officers in Section 7.1 below.

\subsection{Audit Selection Process}

As is the case in many auditing agencies, the selection of entities to be audited depends in part on quantifiable criteria and in part on subjective, qualitative factors. To optimize cost-benefits, auditing agencies tend to target resources on entities that are large enough, and at high enough risk of malpractice to warrant the effort. At the same time, to maintain deterrence power, even small and low-risk entities are subject to some audits. Auditing agencies increasingly use scoring rules to weigh these different considerations.

In 2011-2012, the Chilean Comptroller used a secret scoring system with cutoffs to guide the decision of which public entities to audit. We exploit these cutoffs to measure the impact of being audited using a regression discontinuity design. ${ }^{16}$ Among public entities that the Comptroller considered to be of medium non-compliance risk, the decision to audit depended in part on an "importance score". ${ }^{17}$ This score combined different aspects of entity size such as level and variation of the budget, total assets and liabilities, number of employees in

\footnotetext{
${ }^{16}$ In later years, the scoring rule was changed such that there was no discontinuity anymore.

${ }^{17}$ Almost $59 \%$ of entities were considered medium-risk. Among the $38 \%$ considered high-risk, a large share was audited independently of their importance score, while among the $3 \%$ considered low-risk, few were audited. The risk classification was based on factors like low compliance in previous audits or complaints from civil society.
} 
management, technical professions and other roles, transfer payments to the private sector, as well as sector-specific indicators, such as the complexity of a hospital or the number of health clinics managed by a given health department. An entity's importance score was formed by multiplying these indicators with weights that varied from year to year and were never made public. We find that a unit increase in the importance score is associated with about $3.5 \%$ higher total purchases.

Public entities of medium risk were divided into three groups according to their importance score: high, medium, or low. This ranking and the cutoffs were determined each year separately for each internal unit of the Comptroller. ${ }^{18}$ We therefore refer to a stratum as a cell defined by year and internal unit. Within each internal unit, the Comptroller divided the range of the score into three equally-sized parts that determined the cutoffs. These calculations were kept secret within a small team at the central control office. Neither the existence of the score nor the cutoffs were known to entities subject to the audit. Entities only learned whether or not they had been selected for an audit, no justification was given.

\subsection{Conceptual Framework}

The following provides a simple conceptual framework to illustrate the challenge of avoiding distortions by audit when agents subject to the audit have some discretion over multiple procedures. Beyond procurement, this can apply in many contexts, such as medical professionals choosing to use a shorter or a more complex procedure, sales staff choosing whether to sell a simpler or more expensive but complex service, etc. When agents learn that using the more complex procedure leads to a higher risk of being called out for errors during an audit, this gives them an incentive to avoid this procedure and use the shorter or simpler one instead, even if that procedure is otherwise not optimal.

Consider two such procedures that differ in the number of auditable steps involved in their execution. In our context, the procedure with fewer steps is direct contracting, while the alternative, longer procedure is an auction. Many factors may affect whether agents choose one procedure over the other. In the context of public procurement, these include for example whether there are enough suppliers in the market, or whether the amount of the purchase is large enough to warrant an auction, as well as potential private benefits in

\footnotetext{
${ }^{18}$ Each internal unit is responsible to monitor and audit a group of public entities.
} 
the form of differential opportunities for corruption across procedures. The fact that agents have to take multiple considerations into account is often the reason why they are given some discretion in the choice of procedure. One key consideration we focus on here is that, at each step, agents run the risk of making a mistake leading to an infraction. ${ }^{19}$ For the rest of the discussion, we focus only on this aspect and take other considerations as given.

Agents choose the level of effort to reduce the risk of making infractions, taking into account the effort cost and the expected penalty. At each step, infractions are detected with some probability, and agents receive a sanction per detected infraction. Online Appendix C discusses the auditing agency and the procurement officers' incentives, and derives the framework's implications more formally. It also analyzes considerations regarding whether and how it can be optimal to eliminate the resulting distortions. The framework implies that in settings where agents have no discretion over the choice of procedure, maximization of deterrence for each auditable step independent of procedure has no further implications. However, if agents do have some discretion, this gives rise to a distortionary incentive against procedures with more auditable steps. Switching to a procedure with fewer auditable steps allows agents to reduce their expected detected infractions without increasing effort to avoid mistakes. ${ }^{20}$

Optimal audit design should take these considerations into account. Auditing agencies that are aware of this distortionary mechanism could employ a number of counterbalancing measures. The government could instruct the auditing agency to not only maximize detection of infractions, but to also include minimizing distortions between procedures into the agency's objective function. Additional policy instruments may help mitigate the trade-off. To set correct incentives, the auditing agency may, for example, consider adjusting audit probabilities or penalties. In the case of procurement, this could mean equalizing the number of checks across different purchase procedures or increasing the penalties for infractions committed in direct contracts compared to auctions. In addition, auditors could focus in more

\footnotetext{
${ }^{19}$ In an auction, for example, the agent may write an incomplete specification of the call for bids.

${ }^{20}$ In our procurement setting, officers may shift from auctions to direct contracting when learning that in the event of an audit, auctions lead to more detected infractions and associated sanctions. Such updating can happen when agents are not previously aware of this pattern - for example because audit protocols recently changed or because the auditing agency announces that it will more vigorously pursue the overuse of direct contracts and promote auctions, but leaves the audit protocol unchanged, as was the case in our context.
} 
depth on the key step involved in using a direct contract, i.e. the validity of the justification given for the use of this procedure. Finally, they can increase the overall audit probability for purchases awarded through direct contracting or for entities with higher use of direct contracts (which is what the Chilean Comptroller Agency ended up doing).

\section{Data}

We combine transaction-level data from the Procurement Agency with audit data from the Comptroller. ${ }^{21}$ To complement these administrative data sources, the Comptroller conducted additional audits to collect information on what happens during procurement audits, including which contracts are audited, which checks are executed and what infractions are found. Finally, we conducted a country-wide online survey with procurement officers to shed light on some of the underlying mechanisms, as well as qualitative interviews with procurement officers, suppliers, and auditors.

\subsection{Data on Procurement}

We collected data from the Procurement Agency on the full universe of purchases conducted on the online platform. For each purchase, this includes the purchasing entity, purchase procedure, justification in case of direct contracts, number and characteristics of bidders in case of auctions, date of the purchase, 8-digit product codes, verbal description of each item, value of the purchase, quantity purchased, unit of measurement, and identification number and characteristics of the seller (e.g. firm size, location).

Table 1 Panel A presents summary statistics for the universe of purchases in our estimation period. With 4.4 million purchases for USD 6.6 billion, auctions make up about $51 \%$ of purchases and $64 \%$ of amounts spent, while direct contracts represent around $15 \%$ of purchases and $18 \%$ of amounts spent. The average number of quotes obtained per direct contract is 1.4 , while an average of 13 bidders compete in public auctions. Framework agreements cover about $27 \%$ of purchases, but only $17 \%$ of total dollars spent, as they are commonly used for lower-cost purchases, such as office supplies or cleaning materials. Finally, about $7 \%$ of purchases but less than $0.5 \%$ of the value was for very small purchases, for which use of the electronic procurement platform is optional. The numbers are quite similar when considering only the entities in the estimation sample, i.e., those of medium

\footnotetext{
${ }^{21}$ Our online data documentation appendix explains the construction of the dataset in detail.
} 
risk within a \pm 10 range around the cutoff of the importance score.

\subsection{Data on Audits}

Administrative Data: The Comptroller provided data on audits (which entities were audited and when), on the importance score and the risk classification of each public entity, as well as on the internal unit in charge of monitoring each entity. We also collected information on political affiliations of the leadership of each entity from the Chilean Electoral Service (Chilean Electoral Service, 2014) to construct a control variable. ${ }^{22}$

Additional Audits: Information routinely collected by the Comptroller during audits was rather limited at the time. It included only the detected infractions, but no data on which purchases were audited and what checks were conducted. Findings from many purchases were grouped together, so that it was not possible to study differences by procurement procedure. This limits the scope of possible analyses of what happened during the audits in our RDD sample. To shed more light on the audit process, the Comptroller agreed to undertake additional audits to collect more information. These audits were conducted as usual, with the key difference that auditors recorded more information, namely which contracts were audited, which checks were applied and which infractions were detected for each contract. This allows us to examine differences in the way auctions and direct contracts are audited in terms of the number and type of checks applied and the frequency and severity of detected infractions. The audits in the RDD analysis took place in 2011-2012, while the additional audits were implemented in 2015 (see Figure A2 for a timeline). ${ }^{23}$ However, the audit protocol of the Comptroller had remained unchanged.

The audit protocol includes 95 checks, most of which correspond clearly to either the contract awarding or the contract execution stage. The contract awarding stage includes all steps leading up to awarding of the contract, such as choosing the procurement procedure, writing the specifications for auctions, requesting quotes for direct contracts, and evaluating the bids or offers. The contract execution stage refers to all activities following contract

\footnotetext{
${ }^{22}$ Political affiliations are right-wing coalition, left-wing coalition, or independent. National and regional entities were assigned to the right-wing coalition since they were part of the right-wing coalition government in office at that time. Affiliation of municipal entities was assigned according to the mayor.

${ }^{23}$ The first and second wave of RDD audits were conducted in 2011 and 2012, respectively. Results from the RDD evaluation were obtained in 2014 and qualitative interviews carried out. Additional audits to study the audit content were conducted in 2015. In 2016, we obtained data on additional audits. Lastly, we conducted the procurement officer survey in 2021.
} 
awarding, such as timing of delivery, quality of the product or service, and delivery according to specification. ${ }^{24}$ The additional audits took place in two waves in July and September 2015. Eighteen out of 1,278 entities were selected randomly from internal units that had remaining auditing capacity. In each entity, the Comptroller audited three purchases of goods and up to three purchases of services, for a total of 105 audited contracts. ${ }^{25}$

Survey Evidence: To complement the administrative data, we collected both qualitative and quantitative data from key agents in the procurement process. First, we conducted focus groups and over 50 interviews with auditors of the Comptroller Agency, with procurement officers of over twenty public entities and with owners of supplying firms in 2014-2015. This allowed us to generate testable hypotheses that informed the quantitative analysis. Second, we implemented a country-wide online survey with procurement officers to investigate several aspects of the mechanism. For this, we partnered with the procurement agency to access contact information of procurement officers. The survey was then sent from the researchers' account and clarified that all responses would be treated confidentially. The survey was piloted in June--July 2021 and rolled out in August-November 2021.

The sample frame consists of the universe of public entities for which the data from the Comptroller and the Procurement Agencies could be matched and which had experienced a regular audit in the previous two years. The goal was that respondents would have recently experienced an audit. ${ }^{26}$ Within these entities, we sent the survey to all operators and supervisors for public procurement who had substantial experience with procurement in recent times. $^{27}$ Despite the challenges of Covid-19, we managed to get responses from 213 officers via this online survey, corresponding to a response rate of $27 \%$. Respondents have very similar characteristics to the full sample frame. They have used the system for 5.9 years on average and $52 \%$ are male, while in the sample frame, the mean is 6.1 years and also $52 \%$ are male. Respondents cover half of all entities in the sample frame and come from 13 out

\footnotetext{
${ }^{24}$ Online Appendix B shows the audit protocol and classifies checks by awarding or execution stage.

${ }^{25} \mathrm{~A}$ few entities had less than 3 service contracts during the audited period.

${ }^{26}$ Excluded from the sample frame were any entities that had experienced a different type of audit in the last five years, to avoid any confusion in the responses between the regular audits that this paper studies and special types of audits in which the mechanisms may differ.

${ }^{27}$ The sample consists of officers who have worked in public procurement for at least two years and had used the online system within the last two years.
} 
of the 16 regions in the country. ${ }^{28}$

\section{Empirical Strategy}

\subsection{Regression Discontinuity Design (RDD) Specification}

Based on the audit-selection process described in Section 2.3, we estimate the impact of an audit by comparing entities above and below the cutoffs in the importance score. While these entities are otherwise similar, a higher share of those above the cutoff experienced an audit. We use a fuzzy RDD, since factors other than the importance classification are also taken into account when entities are selected for audit. The RDD captures the effect for entities classified as medium-risk in the vicinity of the cutoffs. In terms of external validity, this implies that we measure impacts on relatively "typical" entities, which are in the middle of the risk distribution and neither extremely large nor extremely small.

Since cutoffs were determined separately in each stratum, we normalize scores at the stratum level, so that the normalized score indicates distance from the cutoff (following e.g. Kaufmann et al., 2013; Pop-Eleches and Urquiola, 2013; Hastings et al., 2014). Our main specifications include stratum fixed effects and entity characteristics as controls. ${ }^{29}$ The location of the significant discontinuity varied across years. ${ }^{30}$ In our period, the discontinuity occurred between low and medium levels of importance in 2011 and between medium and high in 2012. We therefore focus on these two cutoffs in our main specifications. For robustness, we also provide estimates that pool across all four potential cutoffs. The normalized distance to the cutoff ranges from -62.5 to 38.9 .

We use four different specifications: 1) Local linear regressions around the cutoffs following Hahn et al. (2001) and Imbens and Lemieux (2008). 2) Quadratic specification in a larger bandwidth following Lee and Lemieux (2010). Based on visual inspection, these specifications use bandwidths of \pm 4 and \pm 10 respectively. ${ }^{31}$ 3) Outcome-specific bandwidths that are Mean Square Error-optimal using triangular kernels as proposed by Imbens and

\footnotetext{
${ }^{28}$ The non-represented regions are small and cover only $3.2 \%$ of Chile's population.

${ }^{29}$ For robustness, we also run regressions interacting the stratum dummies and distance to the cutoff.

${ }^{30}$ The share of entities audited was generally low among entities with low importance score and high among those with high importance score. For entities in the medium range, the audit rate depended on the available auditing resources in a given year.

${ }^{31}$ These estimations use a rectangular kernel, which in effect amounts to giving higher weight to observations closer to the cutoff.
} 
Kalyanaraman (2012) as well as 4) the same bandwidths with bias-corrected estimates and robust standard errors following Calonico et al. (2014). ${ }^{32}$

The local linear specification for observations within distance $h$ of the cutoff is:

$D_{i s}=\pi \mathrm{I}\left[X_{i s} \geq 0\right]+\rho_{0}+\rho_{1} X_{i s}+\rho_{2} X_{i s} \times \mathrm{I}\left[X_{i s} \geq 0\right]+a_{s}+\gamma W_{i s}+V_{i s}$

$Y_{i s}=\tau \mathrm{I}\left[X_{i s} \geq 0\right]+\beta_{0}+\beta_{1} X_{i s}+\beta_{2} X_{i s} \times \mathrm{I}\left[X_{i s} \geq 0\right]+a_{s}+\theta W_{i s}+U_{i s}$

where $Y_{i s}$ is an outcome for entity $i$ in stratum $s$; $D_{i s}$ a dummy equal to 1 if an entity is audited; $X_{i s}$ the importance score normalized with respect to cutoff $c_{s}, \mathrm{I}\left[X_{i s} \geq 0\right]$ an indicator for an importance score above the cutoff; $\tau$ the effect of crossing the cutoff on outcome $Y_{i s}$; $a_{s}$ the stratum dummies; $W_{i s}$ a vector of entity characteristics; $U_{i s}$ and $V_{i s}$ are error terms. Control variables include: a dummy for having been audited a year prior to treatment, ${ }^{33}$ dummies for entities' political affiliation, as well as first and second lags of $\log (+1)$ of the total amount purchased by the entity, of the shares of spending through auctions and direct contracts, and of the outcome variable (where the outcome is different from auction or direct contracting shares). For robustness, we also show specifications without control variables, and specifications in first differences.

Our analysis of impacts on purchase procedures is at the level of the public entity. For effects on supplier characteristics and prices, we use data at the purchase level to control for additional factors such as month of the purchase and product-unit fixed effects. ${ }^{34}$ Standard errors are clustered at the stratum level. We focus on the reduced form rather than IV estimates, as the reduced form is sufficient to establish whether the audit impacts procurement outcomes. This also allows us to maintain a close correspondence with the graphical evidence and to avoid potential weak instrument problems that could arise with IV in our context (Chernozhukov and Hansen, 2008; Feir et al., 2016).

\subsection{Specification for the Analysis of the Additional Audits}

The data from the additional audits allow us to analyze the audit process by purchase procedure. We run OLS regressions of the number and type of checks and infractions on

\footnotetext{
${ }^{32}$ Originally, we intended to include subgroup analysis by type of entity or product. For this, we developed a new empirical approach based on propensity score reweighting, which allows running RDD analyses by subgroup while holding other characteristics constant (see description and Stata code in Carril et al., 2018). Unfortunately, there is not enough statistical power to detect any potential differential impacts in our data.

${ }^{33}$ Audit data are only available for one year prior to 2011.

${ }^{34}$ These are dummies for each product by unit of measurement, e.g. kilograms of salt.
} 
whether a purchase was done through auction or direct contracting. Clearly, the purchase procedure is not exogenous. We undertake two steps to investigate whether the differences in the number of checks and infractions are indeed related to the purchase procedure and not based on other differences between the purchases.

First, we show that results are robust to the inclusion of key covariates: product dummies, month of the purchase, amount of the purchase, month of the audit, and internal unit implementing the audit. Second, we analyze results separately for the awarding and execution stages of the contract (as defined in Section 3.2). While the awarding process differs substantially between purchase procedure, the execution stage is similar. If differences in the number of checks or detected infractions are mostly concentrated in the awarding stage, this would suggest that the purchase procedure itself is likely driving these results, rather than unobserved differences between purchases made through direct contracts and auctions.

\subsection{RDD Internal Validity Checks}

The RDD effects are identified under two main assumptions. 1) No other characteristics change discontinuously at the cutoff. 2) The exclusion restriction - crossing the cutoff does not affect outcomes through any other channels. As shown in Lee and Lemieux (2010), a sufficient condition for the first assumption is that the density of the variable determining treatment assignment is continuous. This is fulfilled if there is no precise manipulation to be on either side of the cutoff. This is likely the case here for the following reasons. As discussed above, the existence of a score is unknown to public entities. In addition, the cutoffs are determined after all scores have been calculated, and are based on the range of the score in each stratum. So entities would not only need to know their own score, but also every other entity's score to be able to locate precisely to the left of the cutoff. Moreover, the components and weights of the importance score change each year. Finally, the fact that the cutoff does not shift the share of audited entities from zero to one reduces the incentives for such manipulation. If a control department and a public entity wanted to collude, it would be easier to simply not select that entity for audit rather than manipulate its score.

While the assumption of continuity is not directly testable, it has testable implications. Figure 1 shows results of a McCrary density test (McCrary, 2008). Consistent with no manipulation, the test does not reject the null hypothesis that the density is smooth around 
the cutoff $(\log$ difference $=-0.1$, standard error $=0.2$ ). Table 2 tests for imbalance of covariates at the cutoff by running RDD analyses for each covariate as the outcome, as in Equation (2). Columns (1) and (4) show comparison means, i.e. estimated means to the left of the cutoff in the \pm 4 and \pm 10 range, respectively. Each coefficient in Columns (2)(3) and (5)-(6) shows the result of a separate regression to test for discontinuity. Columns (2) and (3) show linear discontinuity estimates in the \pm 4 range without and with stratum fixed effects. Columns (5) and (6) show the same for quadratic estimates in the \pm 10 range. Variables are either time invariant or from the pre-treatment period. The F-statistic is from a test of the joint hypotheses that all discontinuities in a given column are zero. The p-values for joint significance range from 0.59 to 0.74 , indicating no significant discontinuity at the cutoff. However, not all characteristics have point estimates that are close to zero, and in one of the four specifications, a pre-treatment outcome is significantly different from zero at the $10 \%$ level. Our preferred specifications therefore control for all variables in Table 2. For outcomes other than direct contracting and auction shares, we also control for the first and second lags of the outcome variable. Finally, we also show impacts on the main outcomes (purchases via auction and direct contracts) on a quarterly basis over time, to confirm that the impacts start at the time of the audit.

The exclusion restriction is unlikely to be violated given that the running variable is an internal score constructed by a small unit within the Comptroller Agency, not shared with other departments. Moreover, the score is different for every stratum and in every year. In our extensive conversations with many representatives at the Comptroller Agency, it became clear that this score was not used for any other purpose.

\section{$5 \quad$ First Stage and Impacts on Purchase Procedures}

\subsection{RDD First Stage: Effect on the Share of Audited Entities}

Figure 2 presents first stage results pooling across 2011 and 2012. ${ }^{35}$ The $\mathrm{x}$-axis represents the importance score normalized by stratum-specific cutoffs. The y-axis shows the residual share of audited entities after controlling for stratum fixed effects and the control variables.

\footnotetext{
${ }^{35}$ As discussed in Section 4.1, based on the audit selection process, the significant discontinuity can differ for different years. It occurs between low and medium levels of importance in 2011 and between medium and high in 2012. Our main specifications therefore focus on these cutoffs. For robustness, we also report estimates pooling all four potential cutoffs. See Table A1 in the Appendix for the corresponding first stage.
} 
Each dot represents a two-point wide bin. Linear and quadratic fitted lines are also included. A number of aspects stand out. First, there is a jump in the share of audited entities at the cutoff. Second, the share of audited entities is generally increasing with the importance score (i.e. moving from left to right in the figure), but this increase is not linear. As discussed above, the choice of which entity to audit within a level of importance is based on subjective considerations, which can result in non-linearities. This does not affect our estimates, which are based solely on the discontinuity at the cutoff.

Table 3 displays the first stage numerically for 8 specifications: Columns (1) to (3) show a bandwidth of \pm 4 with a linear local polynomial and Columns (4) to (6) a bandwidth of \pm 10 with a quadratic local polynomial with varying inclusion of covariates. Column (7) employs the optimal bandwidth proposed by Imbens and Kalyanaraman (2012) and Column (8) adds bias-corrected RD estimates and robust standard errors proposed by Calonico, Cattaneo and Titiunik (2014). All estimates are statistically significant at the $5 \%$ or $1 \%$ level. In our preferred specifications with control variables, i.e. Columns (3), (6), (7) and (8), the share of audited entities increases at the cutoff by 15.8 to 19.3 percentage points.

\subsection{Effects on Purchase Procedures}

Next, we analyze the impact on the share of spending by procurement procedure. Figure 3 presents the graphical evidence. Public entities just to the right of the cutoff have a lower share of spending through auctions (Panel A) and a higher share of direct contracts (Panel B). The similar magnitude and opposite direction suggest that entities increase direct contracts at the expense of auctions. Panels $\mathrm{C}$ and $\mathrm{D}$ show no impacts on procurement made through framework agreements or as small purchases.

Table 4 displays the results for auctions and direct contracts in regression form, following Equation (2). Results are quite robust across specifications, even though magnitudes and levels of significance vary. In our preferred specifications, i.e. including control variables, the estimates range from -6.9 to -8.9 percentage points for auctions and from 6.1 to 7.7 percentage points for direct contracts. Undergoing an audit therefore seems to induce public entities to reduce the use of the more transparent and competitive procedure of public auctions and to increase the use of direct contracts. ${ }^{36}$

\footnotetext{
${ }^{36}$ For robustness, we also estimate these effects including interactions between stratum dummies and
} 
While the reduced form estimates above are sufficient to establish whether the audit impacts procurement outcomes, measuring the magnitude of the impact of an audit would require scaling them up by the inverse of the first stage. This would suggest an impact of 34 to 41 percentage points in the specifications with controls for the shift towards direct contracts and 38 to 48 percentage points for auctions, which seems quite large. However, these point estimates have to be interpreted with caution for two reasons. First, the IV standard errors are very large, making the specific point estimate less informative. Second, and more importantly, the first stage estimates may be too weak to provide reliable IV inference (Chernozhukov and Hansen, 2008; Feir et al., 2016). Specifically, the first stage F-statistics in our preferred specifications (Table 3) range from 5.3 to 6.9, while the critical value of an F-test for a size distortion of no more than 5 percentage points for a 5 percent significance test is about 16.4 (Andrews et al., 2019).

To further assess whether the effect indeed stems from the audits, we also show the evolution of the effect over time. Figure 4 shows the effects on a quarterly basis for two years before to two years after the beginning of the audit. While the quarterly results are relatively noisy, there is no impact in the pre-treatment periods. The effect starts at the beginning of the audit year and grows over the course of that year. This may reflect that, as discussed above, entities begin to learn about the content of the audits in the first part of the year, and additional information is revealed over the course of the process. Procurement officers gradually learn that, despite the government's recent increased push for auctions, they run a higher risk of being scrutinized and called out for infractions in auctions rather than in direct contracting (as shown in Section 7).

The effect then starts to decrease over the following year. In year 2 , the effect is about half in magnitude of year 1 (see Table A5). It might seem a priori surprising that it is relatively short-lived. If the shift to fewer auctions is a result of entities learning during the audits that purchases made by auction undergo more scrutiny than those made through direct contracts, one might expect the effect to be permanent. Several factors could drive

distance to the cutoff (Table A2). This allows for the relationship between outcome and running variable to differ within each stratum. Results are quite similar. We also show reduced form estimates pooling across all four potential cutoffs (Table A3). Results are similar in terms of the sign of the effects but with smaller coefficients when pooling across all four potential cutoffs, as expected given the smaller first stage . Finally, Table A4 shows the effect on the first differences of auctions and direct contracting. 
this dynamic. On the one hand, the difference between treated and comparison entities falls when comparison entities catch up. This can happen for two reasons. First, many entities that are below the cutoff in one year are audited in the following year. Second, information that the audit protocol did not reflect the recent official push for more use of auctions is likely to spread among procurement officers across the different entities. ${ }^{37}$ On the other hand, the effect may have waned within the treated entities themselves, both due to staff turnover and because entities could reasonably expect that the audit protocol would continue to evolve due to further regulatory changes (Chile Compra, 2016). Overall, the results of Section 5.2 suggest that being audited induced entities to reduce the use of auctions for their subsequent purchases and increase the use of direct contracts instead.

Direct Contracting Justifications: Entities need to provide a justification for using direct contracts. Analyzing which justifications drive the higher use of direct contracting in audited entities can shed additional light on the mechanism. Table A6 shows RDD estimates for the five most frequent justifications and all other justifications grouped together. Recall that the shift towards direct contracting is around 7 to 9 percentage points of amounts purchased. Over half of this increase is based on the emergency justification. Direct contracting using the emergency justification is 4 to 5 percentage points higher above the threshold, compared to the base share of 0.8 to 1.4 percentage points. All specifications are significant at the $1 \%$ or $5 \%$ level. Direct contracts using the unique supplier justifications start at a higher base share of around 2.5 percentage points and increase by 1.2 to 1.8 percentage points (varying from insignificant to significant at the 5\%-level). The coefficients for the other justifications are small and not significant.

The finding that the increase in direct contracting is driven to a large degree by emergency justification is consistent with the interpretation that after an audit, procurement officers intentionally increased the use of direct contracting, using the justification that is the easiest to manipulate. The emergency justification is known to be particularly prone to overuse and even mentioned as such in the regulation. This is both because it is difficult to monitor ex-post, whether a purchase was indeed urgent, and because if a buyer waits long

\footnotetext{
${ }^{37}$ Results from the country-wide procurement survey reveal that $80 \%$ of officers learn about the auditing process from other public entities. The most frequent channels are joint trainings or meetings, documents, and conversations with officers from other entities. Information also flows indirectly from colleagues in the same entity who have information from another entity (see Figure A3).
} 
enough, almost any purchase can become justifiable on emergency grounds (Robinson and Weigel, 2018).

Product Choice and Total Spending: One concern regarding the interpretation of the results may be that the change in purchase procedure might be driven by a change in product choice. To test this hypothesis, we analyze the impact of undergoing an audit on the share of spending by procurement procedure using product-level procurement shares with productlevel fixed effects. The dependent variable in this analysis is the share of spending through auctions/direct contracts, respectively, out of total spending on a given product by a given entity. In order to account for the importance of different products in an entity's spending composition, the regression weighs each observation with the share of the corresponding product in an entity's total spending. Our findings are very robust to these product-level specifications, as shown in Table 5 .

We also analyze whether there is a discontinuity in auction and direct contract shares purely based on the product mix, using the pre-treatment shares of purchase procedures for each product. We proceed as follows. First, for each 8-digit product we calculate the share of spending on that product that is done through each purchase procedure in year $t-1$. For each entity, we then construct the auction and direct contracting shares that would be expected under the actual (potentially shifted) product mix from year $t$ but using the above product-level procedure shares that are constant based on year $t$-1. If a changed product mix (towards less auction-intensive and more direct contract-intensive products) were driving our results, we would expect a similarly sized impact on these expected auction and direct contract shares as we find in our main analysis. ${ }^{38}$

Appendix Table D1 shows the results, which confirm that the shift from auctions to direct contracting is not a result of a shift towards less auction-intensive and more direct contract-intensive products: The discontinuity estimates at the cut-off are close to zero and

\footnotetext{
${ }^{38}$ In detail, we proceed as follows. First, for each 8-digit product $q$, we calculate $P$, the share of spending on that product that is done through each purchase procedure $j$, in the year before the audit: $P_{q, j, t-1}=$ $\frac{\sum_{i} \text { Spending }_{i, q, j, t-1}}{\sum_{j} \sum_{i} \text { Spending }_{i, q, j, t-1}}$, where $i$ denotes a given entity and purchase procedures are direct contracting, auctions and other. $P_{q, j, t-1}$ are constant across entities. We then compute for each entity $i$ the share of spending on product $q$ out of total spending by that entity in year $t: S_{i, q, t}=\frac{\text { Spending }_{i, q, t}}{\sum_{q} \text { Spending }_{i, q, t}}$. Our new outcome variable is then the expected spending share by entity $i$ through purchase procedure $j$, based on the actual product mix in year $t$ and procedure shares of these products in year $t-1: Y_{i, j}=\sum_{q} S_{i, q, t} P_{q, j, t-1}$.
} 
the confidence intervals exclude the effects found in our main analysis (i.e. -0.089 for auctions and +0.077 for direct contracting, as shown in Table 4 Column (8)).

We provide two sets of additional analyses regarding product choice, also shown in Online Appendix D. First, we analyze whether audits led to a change in the type of products purchased. We look at the impact on the spending share for each product for the 6 main product groups as well as at the more disaggregated levels of 2-digit and 8-digit product codes. There was no systematic product shift at any of these levels of disaggregation (Appendix Table D2). Second, we test the robustness of the impacts on procurement procedures using a subset of products which have a meaningful choice of purchase procedure, i.e. where not almost all of the purchases of this product are made through one procedure. Appendix Table D3 shows that the impact on purchase procedures is very similar for these products as well.

Another question that might arise is whether the shift in procurement procedures might stem from a change in total spending. Table A7 shows that this is not the case. ${ }^{39}$ Finally, to understand the relevance of the procedure shift it is also interesting to look at the size of the affected contracts. Are the effects concentrated on relatively small purchases for which using an auction may not be worthwhile? Table A8 shows that on the contrary, the shift seems to stem mostly from contracts of above-average size.

\section{Effects on Competition, Suppliers and Prices}

Competition: One reason many governments promote auctions over direct contracting is that auctions are believed to be more competitive. However, a move from auctions to direct contracting does not necessarily imply a decrease in the number of competitors, since some auctions only attract a small number of bidders and certain direct contracts require 3 quotes from different firms. If the reduction in auctions stems mainly from auctions with few bidders, while the increase in direct contracting stems mainly from cases requiring three quotes, the number of competitors involved might not actually fall or could in principle even increase. Table A9 presents regression results estimating the impact on auctions and direct contracts with high vs. low number of competitors. Following the Procurement Agency's

\footnotetext{
${ }^{39}$ This is not surprising, since Chilean legislation does not allow entities to deviate substantially from their budget.
} 
assessment, we classify an auction as competitive if it has more than 3 bidders. Panels A and B show that most of the shift goes from competitive auctions to direct contracts requiring only 1 quote. The reduction in auction share is, if anything, larger among auctions with more than 3 bidders. At the same time, the entire increase in direct contracts stems from purchases based on only one quote. Overall, there is a reduction in the share of purchases made through a competitive process (more than 3 competitors) by 5 to 8 percentage points. Type of Suppliers: One important measure of whether there were real economic impacts beyond the reduction in the number of competitors is whether this affected the type of supplier that won contracts. Less competition might benefit incumbent firms with prior contracts with the procuring entities (Coviello et al., 2018), smaller firms that might not be able to compete in an open competition and local suppliers who might have more connections with the procuring entities (Lewis-Faupel et al., 2016). When analyzing effects on the type of suppliers that win the contracts, an additional assumption is required to attribute these effects to the procedure shift: that the audits do not have a direct effect on these outcomes. Specifically, being audited cannot induce public entities to sell more to incumbent, small, and local firms for other reasons than the shift from auctions towards direct contracts. A similar assumption is required for the analysis of impacts on prices in the next subsection. While this is not testable, if anything, it would seem plausible to expect the direct effect of an audit to go in the opposite direction (consistent with findings by Colonnelli and Prem, 2022).

Table 6 displays impacts on supplier characteristics. Panel A shows a reduction for new suppliers that have not sold to this entity before (within the 4 preceding years for which we have data). Their probability to win a contract falls by 2.4 to 4.6 percentage points. This is quite substantial compared to the baseline probability of around $17 \%$. The coefficient is statistically significant for three out of our four main specifications. Panel B shows that the probability of large firms winning contracts also falls by between 4.8 and 7.2 percentage points from a baseline of around 30\%. ${ }^{40}$ The effect is significant at the $1 \%$ or $5 \%$ level. Finally, Panel $\mathrm{C}$ analyzes the impact on suppliers from another region. The chance of suppliers to win a government contract falls by between 3.4 and 6.5 percentage points from

\footnotetext{
${ }^{40}$ The Chilean tax authority officially classifies firms with over about USD 4 million in sales as large.
} 
a baseline of around $45 \%$, significant at the $5 \%$ to $10 \%$ level. ${ }^{41}$

Overall, these results show real impacts on suppliers. The fact that the shift away from auctions came with an increase of contracts given to small, local, incumbent suppliers is consistent with the view that direct contracting facilitates favoritism of insiders with special connections to the procuring entity.

Prices: The shift towards less competition and more incumbent, small, and local suppliers raises the question whether this leads to higher prices. However, measuring impacts on prices is notoriously difficult, and we will have to restrict this analysis to a small subgroup of products for which this is possible. There are three challenges in this regard. First, for many purchases there are no clear units of measurement in the data. Purchase orders may contain measures such as "a sack of rice", "a month's supply of gas", or a "training workshop in IT". Such vague units do not allow for a reliable comparison of prices. We therefore have to restrict the analysis to purchases with clear units of measurement such as meters, liters, or kilograms. This leaves about $7.6 \%$ of the total number of purchases and $2.2 \%$ of the value of purchases. ${ }^{42}$ This price analysis therefore does not necessarily generalize to other types of purchases. Impacts on purchases without comparable units, such as many services, may be different. In particular, selection criteria for such purchases are typically more difficult to specify ex-ante, making it more challenging to procure them efficiently through auctions.

The second challenge is that when we implement the RDD among products with clear units of measurement, there is no significant overall shift in purchase procedure. This may be expected, since these products are more standardized and therefore more likely to be always purchased through the same procedure, including framework agreements. To be able to analyze a sample in which there actually is a shift in procurement procedure, we do the following. First, we run RDD regressions for each product to estimate the shift in the auction share. We then divide products into two groups: those with above-median and those with below-median absolute size of procedure shifts. The analysis of the impact on prices

\footnotetext{
${ }^{41}$ The analysis by region excludes entities in the Metropolitan Region (RM), since a large part of the Chilean economy is based there, so that the vast majority of purchases by entities in that region are from firms in the same region. This analysis therefore focuses on purchases from entities in other regions, for which it is more likely that competitive suppliers exists outside the region. Table A10 shows results including entities from RM. As expected, estimates are much smaller.

${ }^{42}$ The biggest categories among purchases with comparable units of measurement are foods, fuel and hardware. The biggest category of purchases with non-comparable units are services (60\% of the value).
} 
focuses on the former group. In the below-median effect group, as expected, we find no effect on prices. Third, while we control for 8-digit product fixed effects and focus on products with comparable units, we cannot control for potential unobserved quality differences. It is possible that having more discretion when using direct contracts, purchasing officers choose supplies with unobserved higher quality. At the same time, it is important to remember that auctions in Chile are not first price, but scoring auctions, which allow purchasing entities to award contracts based on points for quality and previous supplier experience as well.

Table 7 shows RDD estimates on the log of unit prices in the sample of products with comparable units and above-median procedure shift. Prices increase quite substantially, by about 10 to $15 \%$, significant in 3 out of the 4 specifications. ${ }^{43}$ Combined with the finding above of a shift towards lower competition and different types of suppliers, these results suggest that there were real economic distortions resulting from the audits.

\section{Mechanisms}

\subsection{Differential Scrutiny of Auctions and Direct Contracts}

In order to gain a better understanding of the mechanisms that could lead to the impact of audits on the purchase procedure, we worked with the Comptroller to collect more detailed data through additional audits. This allows us to compare the audit process for purchases made through auctions with those made through direct contracts.

Figure 5 displays the number and type of checks and detected infractions by whether a purchase was done through auction or direct contracting. The left-hand set of bars in Panel A show that purchases made with direct contracts undergo around 19 checks on average. In contrast, contracts made through auctions undergo about 32 more checks, for a total of almost 51 checks on average, 2.7 times as many as direct contracts.

As discussed in Section 4.2, we deal with the potential differences in the type of contracts for which auctions and direct contracts are used in two ways. First, we add purchase-level controls for the amount of the purchase and product codes, month of purchase, responsible internal unit, and month of the audit. Table A12 in the Online Appendix shows the same analysis as in Figure 5 in regression form, both with controls (Panel A) and without (Panel

\footnotetext{
${ }^{43}$ As a robustness check, Table A11 shows the results for purchases selected using entities in the \pm 10 bandwidth. The estimates are quite similar.
} 
B). The number of additional checks for auctions is 31.67 with controls and 31.74 without. Reassuringly, the results thus change very little, while the R-squared increases substantially to over 0.9 , which does not leave much room for bias from unobserved factors.

Second, we analyze impacts separately for the contract awarding stage (which is directly affected by the purchase procedure) and the execution stage. The middle and right-hand set of bars in Panel A show the number of checks separately for these stages. About $90 \%$ of the difference in the number of checks between purchase procedures stems indeed from the awarding stage. The number of checks in the awarding stage is 4.9 times larger for auctions than for direct contracts. This suggests that the bulk of the difference is related to differences in the procurement procedure. ${ }^{44}$ If the difference in the number of checks resulted from other unobserved factors, such as project complexity, this would be expected to also lead to more checks in the contract execution stage. Again, adding the control variables changes point estimate very little: Without controls, the number of additional checks in the awarding stage is 28.29 , with controls it is 28.54 , while the R-squared increases substantially to 0.93 .

Next, we analyze whether the higher number of checks results in more detected infractions. The left-hand set of bars in Panel B show that purchases via direct contracts have an average of 1.8 detected infractions. Purchases by auction have 2.7 additional detected infractions. The middle- and right-hand set of bars in Panel B show detected infractions separately for the awarding and the execution stage. Over $80 \%$ of the difference in detected infractions stems from the awarding stage. Table A12 shows all these results in regression form. In addition, Column (7) displays the probability of a contract having a detected infraction so serious that it is marked for a formal follow-up investigation to determine individual responsibilities and sanctions for the infraction. The likelihood of such a follow-up investigation is twice as high for auctions as for comparable direct contracts (24\% vs. 12\%).

Beliefs about Consequences of Detected Infractions: Given the higher number of detected infractions for auctions vs. direct contracts, the question arises whether the consequences are severe enough to cause officers to change behavior. We investigate this question in our procurement officer survey from two angles: 1) we ask about the types of consequences

\footnotetext{
${ }^{44}$ The few additional checks in the execution stage could either be a result of auditors conducting more checks in the execution stage in cases where they find more infractions in the awarding stage, or it could be due to remaining unobserved differences.
} 
of detected infractions for the responsible procurement officers, and 2) we elicit the perceived severity of such consequences. (For details, see Online Appendix E.)

First, respondents were asked about the consequences of detected infractions for the responsible procurement officers. ${ }^{45}$ Figure E1 shows the percentage of respondents who indicated that a given consequence was very likely. While much of the analysis of deterrence from audits - building on the seminal model of crime by Becker (1968)-has focused on formal sanctions, these results show that other consequences can play an important role, including career concerns, social-image and self-image concerns. In terms of career concerns, $45 \%, 66 \%$ and $28 \%$, respectively, say that impacts on the professional career, reprimands by supervisors and work-place harassment are very likely. Regarding social image concerns, over half say that detected infractions are very likely to affect professional prestige and about one third indicate this for shame vis-à-vis supervisors. About half believe they would very likely experience personal feelings of inadequacy. Almost everyone agrees that there would likely be additional work. In contrast, less than $20 \%$ indicate that penal sanctions, demotions or dismissals are very likely.

The question then arises how severe such consequences are for affected officers. To quantify the perceived severity, we used a vignette approach. Officers were asked to indicate for a number of situations how bad they would be for them on a scale from 0 to 10 . The first scenario concerns the type of infractions that our study audits showed to be more likely for auctions, while the other vignettes involve financial losses. Our analysis reveals that officers perceive the consequences of the type of infractions detected in our study audits as severe. Figure E2 shows that $73 \%$ of officers rank the consequences of the detected infractions as equally severe or more severe than a salary reduction of $5 \%$, and $84 \%$ do so regarding a $5 \%$ additional expense in the coming month.

Overall, these findings show that purchases made through auctions are subject to more scrutiny than those via direct contracts. Procurement officers who follow the government's new recommendation and use auctions for their purchases are therefore more likely to be found incompliant in an audit compared to those who use more direct contracts. As a result,

\footnotetext{
${ }^{45}$ We created this list of potential consequences based on extensive piloting of the survey, which included open answers, qualitative interviews, as well as points raised by referees.
} 
this mechanical "auditing by checklist" approach may inadvertently discourage auctions. In our setting, it is likely that procurement officers update their beliefs on how audits are implemented because the government recently changed its stance on the importance of auctions and indicated that it would more vigorously enforce the use of auctions rather than direct contracts. Procurement officers who realize that the current auditing protocol leads to more scrutiny for auctions compared to otherwise similar direct contracts may choose to reduce their use of - already more work-intensive - auctions and increase the use of direct contracts instead. More generally, mechanically checking each step of a regulation, as is done in many audits, may disincentivize the use of processes that involve more steps and leave a longer paper trail.

\section{$7.2 \quad$ Alternative Explanations}

Does the Subsequent Audit Probability Fall? One alternative hypothesis we originally considered was a change in the subsequent audit probability. Specifically, entities might increase direct contracts in year $t$ if the likelihood of a re-audit in year $t+1$ were low, and contracts awarded in year $t$ would therefore be less subject to scrutiny. However, both administrative data and survey evidence show that this is not the case. As Table A13 shows, the audit probability in year $t+1$ is not lower to the right of the cut-off, but if anything even slightly higher (not statistically significant). ${ }^{46}$

The survey evidence also reveals that the vast majority of officers are aware that the scrutiny does not fall after an audit. Only $4.2 \%$ of respondents believe that contracts made during the year of an audit are less likely to be audited because the subsequent audit probability falls in the year after an audit. ${ }^{47}$

Congestion: Another hypothesis we originally considered was that audits might increase

\footnotetext{
${ }^{46}$ The overall probability that an entity in our sample which is audited in year $t$ is audited again in year $t+1$ is $44 \%$ in the \pm 4 bandwidth, and $49 \%$ in the \pm 10 bandwidth, (while the unconditional audit probability in year $t$ is 25\%). Note that these are not the overall audit probabilities in the country, but those of entities considered "medium-risk". The audit probability of "low-risk" entities is close to zero.

${ }^{47}$ This is consistent with statements made in focus groups and qualitative interviews we conducted in 2014-15 with both procurement officers at over twenty public entities and auditors at the Comptroller Agency. Both procurement officers and auditors asserted that it would be unreasonable for procurement officers to expect less scrutiny following an audit for two reasons: First, they (correctly) asserted that the audit probability was not lower in the year following an audit. Second, even if the audit probability were to temporarily fall, that would not leave entities "protected" from scrutiny, since audits typically covered contracts from several prior years.
} 
the workload for officers to the point that they fall behind on procurement work, leaving them with less time to implement auctions and leading them to resort to direct contracting. However, both qualitative interviews and survey evidence revealed that this hypothesis was unrealistic. Officers reported that the audits were only minimally disruptive, since there was little interaction with auditors and all that was required of them was to provide the auditors with documentation of past procurement processes. In the procurement officer survey, we elicited information about the time burden of audits and potential delays. The median number of hours over the entire auditing process was 5. Not surprisingly, given this limited time burden, less than $4 \%$ of procurement officers said that this ever resulted in delays leading to the use of a direct contract with emergency justification (the main type of direct contract for which we see an increase).

\section{Conclusion}

This paper investigates the role of audit design in the context of public procurement in Chile. We first analyze the impacts of government audits on procurement practices. Contrary to the official policy goal, audits led to a reduction in the use of public auctions and a corresponding increase in the use of the less transparent and less competitive purchase procedure of direct contracting. The increase is concentrated among direct contracts justified by emergency, which are particularly prone to overuse and only require a quote from one firm. At the same time, there is a large reduction in auctions with more than 3 bidders, so the overall competitiveness of the procurement process falls. The reduction in competition seems to have had real economic impacts, hurting new, large, and out-of-region suppliers, who are less likely to win the contracts. This type of favoritism risks undermining entrepreneurship and innovation, as it creates barriers for new entrants. In addition to the effect on suppliers, we also find suggestive evidence of a price increase in the subset of products with clear units of measurement and for which there is a substantial shift from auctions to direct contracts.

To shed light on the underlying mechanisms, we worked with the Comptroller to collect more information through additional audits. Results from these audits show that holding the amount and type of purchase constant, auctions undergo about 2.7 times as many checks as purchases through direct contracts and lead to twice as many detected infractions and follow-up investigations. This is concentrated in the awarding stage of the procurement 
process, where the purchase procedure makes a big difference, rather than in the execution stage, where the process is similar, independently of the procedure.

When procurement officers in public entities realize that they are more likely to be called out for infractions when using auctions, it can discourage them from using this purchase procedure even though the regulation aims to promote it. This pattern points to a more general issue: When audit protocols follow a simple checklist approach, which is standard in many settings, more heavily regulated processes with more steps, which leave a longer paper trail, may mechanically lead to more checks during an audit. If agents risk making a mistake in any given step of the process, procedures involving more steps will lead to a higher probability of being found to be incompliant. This can create unintended distortions.

Avoiding such distortions is a big challenge for anyone designing audit systems - both in the public or private sector - when audit protocols differ by procedure and when agents have some discretion over the choice of procedure. All else equal, institutions may want to equalize the expected cost of being audited across the different procedures. To set correct incentives, they may consider adjusting audit probabilities or penalties in order to counterbalance the fact that some processes involve more auditing checks. In the case of procurement this could mean equalizing the number of checks across different purchase procedures or increasing the penalties for infractions committed in direct contracts compared to auctions. In addition, auditors could focus in more depth on the key step of a direct contract, i.e. the validity of the justification given for the use of this procedure. Finally, they can increase the overall audit probability for purchases awarded through direct contracting or for entities with higher use of direct contracts.

Overall, these results suggest that it is key not to think of audits merely as "neutral" verification and information extraction mechanisms, but to carefully consider potential impacts and incentives created by the specifics of the audit design. This is in line with a growing number of findings showing that details of institutional design can have important impacts (Duflo, 2017). Given the widespread use and important function of audits, the audit design can have fundamental consequences for the functioning of the state and the private sector. While there is a large literature related to audit probabilities and detection risk, little economic research has focused on the incentives created by the audit design itself. Audit pro- 
cedures are often developed by lawyers and administrative specialists. Getting economists involved in audit design promises high returns. 


\section{References}

Advani, Arun, William Elming, and Jonathan Shaw, "The dynamic effects of tax audits," The Review of Economics and Statistics, 2021, pp. 1-45.

Andrews, Isaiah, James H. Stock, and Liyang Sun, "Weak Instruments in Instrumental Variables Regression: Theory and Practice," Annual Review of Economics, 2019, 11 (1).

Arizona Auditor General Office, "Procurement-USFR VI-G and R7-2-1001 et seq," 2020.

Auriol, Emmanuelle, Stéphane Straub, and Thomas Flochel, "Public Procurement and Rent-Seeking: The Case of Paraguay," World Development, 2016, 77 (C), 395-407.

Avis, Eric, Claudio Ferraz, and Frederico Finan, "Do Government Audits Reduce Corruption? Estimating the Impacts of Exposing Corrupt Politicians," Journal of Political Economy, 2018, 126 (5), 1912-1964.

Bajari, Patrick, Robert McMillan, and Steven Tadelis, "Auctions versus Negotiations in Procurement: An Empirical Analysis," Journal of Law, Economics, ES Organization, 2009.

Baltrunaite, Audinga, Cristina Giorgiantonio, Sauro Mocetti, and Tommaso Orlando, "Discretion and supplier selection in public procurement," The Journal of Law, Economics, and Organization, 2021, 37 (1), 134-166.

Bandiera, Oriana, Andrea Prat, and Tommaso Valletti, "Active and Passive Waste in Government Spending: Evidence from a Policy Experiment," American Economic Review, 2009.

_, Michael Carlos Best, Adnan Qadir Khan, and Andrea Prat, "The Allocation of Authority in Organizations: A Field Experiment with Bureaucrats," Quarterly Journal of Economics, 2021, 136 (4), 2195-2242.

Banerjee, Abhijit, Rema Hanna, Jordan Kyle, Benjamin A. Olken, and Sudarno Sumarto, "Private Outsourcing and Competition: Subsidized Food Distribution in Indonesia," Journal of Political Economy, 2019, 127 (1), 101-137.

Barrot, Jean-Noël and Ramana Nanda, "The Employment Effects of Faster Payment: Evidence from the Federal Quickpay Reform," The Journal of Finance, 2020, 75 (6), 3139-3173.

Becker, Gary, "Crime and Punishment: An Economic Approach," Journal of Political Economy, 1968, 76 (2), 169-217.

Benabou, Roland and Jean Tirole, "Laws and Norms," NBER WP 17579, 2011.

Bosio, Erica, Simeon Djankov, Edward Glaeser, and Andrei Shleifer, "Public procurement in law and practice," American Economic Review, 2022, 112 (4), 1091-1117.

Bursztyn, Leonardo and Robert Jensen, "Social Image and Economic Behavior in the Field: Identifying, Understanding, and Shaping Social Pressure," Annual Review of Economics, 2017.

Calonico, Sebastian, Matias D. Cattaneo, and Rocio Titiunik, "Robust Nonparametric Confidence Intervals for Regression-Discontinuity Designs," Econometrica, 2014, 82 (6).

Carril, Alvaro, Andre Cazor, Maria Paula Gerardino, Stephan Litschig, and Dina Pomeranz, "Subgroup Analysis in Regression Discontinuity Designs," 2018. https://ideas.repec.org/c/boc/bocode/s458429.html.

Carril, Rodrigo, "Rules versus Discretion in Public Procurement," BGSE WP 1232, 2021.

Carrillo, Paul, Dave Donaldson, Dina Pomeranz, and Monica Singhal, "Misallocation in Firm Production: A Nonparametric Analysis Using Procurement Lotteries," 2022.

_, Dina Pomeranz, and Monica Singhal, "Dodging the Taxman: Firm Misreporting and Limits to Tax Enforcement," American Economic Journal: Applied Economics, 2017, 9 (2).

Chernozhukov, Victor and Christian Hansen, "The Reduced Form: A Simple Approach to Inference with Weak Instruments," Economics Letters, 2008, 100 (1), 68-71.

Chile Compra, "Modificaciones al Reglamento de Compras Públicas," 2009.

_ , "Guía Rápida," 2010.

_ , "Nuevas Capacitaciones por Cambios al Reglamento 19.886 de Compras Públicas," 2010. 
_, "Se Publican Nuevas Guías y Manuales sobre Modificaciones a Reglamento de Compras Públicas," 2010.

_ , "Bienvenido al Mundo de las Compras Públicas," 2012.

_ , "Contrataciones a través de Trato o Contratación Directa," 2016.

_ , "Compras Históricas del Estado," 2018. http://datosabiertos.chilecompra.cl/Home/Compra Historica (accessed 17-Oct-2018).

Chilean Electoral Service, "Elecciones Alcaldes 2004-2012," 2014.

Chu, Jian, Raymond Fisman, Songtao Tan, and Yongxiang Wang, "Hometown Favoritism and the Quality of Government Monitoring: Evidence from Rotation of Chinese Auditors," 2020.

Colonnelli, Emanuele and Mounu Prem, "Corruption and firms," The Review of Economic Studies, 2022, 89 (2), 695-732.

Coviello, Decio and Mario Mariniello, "Publicity Requirements in Public Procurement: Evidence from a Regression Discontinuity Design," Journal of Public Economics, 2014, 109, 76-100.

_, Andrea Guglielmo, and Giancarlo Spagnolo, "The Effect of Discretion on Procurement Performance," Management Science, 2018, 64 (2), 715-738.

_ , _ , Clarissa Loti, and Giancarlo Spagnolo, "Procurement with Manipulation," CEPR DP 17063, 2021.

DeBacker, Jason, Bradley Heim, Anh Tran, and Alexander Yuskavage, "Legal Enforcement and Corporate Behavior: An Analysis of Tax Aggressiveness After an Audit," Journal of Law and Economics, 2015, 58 (2), 291 - 324.

_, Bradley T. Heim, Anh Tran, and Alexander Yuskavage, "Once Bitten, Twice Shy? The Lasting Impact of Enforcement on Tax Compliance," The Journal of Law and Economics, 2018, 61 (1), 1-35.

Decarolis, Francesco, "Awarding Price, Contract Performance, and Bids Screening: Evidence from Procurement Auctions," American Economic Journal: Applied Economics, 2014, 6 (1).

_, Giancarlo Spagnolo, and Riccardo Pacini, "Past Performance and Procurement Outcomes," NBER WP 228142020.

_ , Leonardo M Giuffrida, Elisabetta Iossa, Vincenzo Mollisi, and Giancarlo Spagnolo, "Bureaucratic competence and procurement outcomes," The Journal of Law, Economics, and Organization, 2020, 36 (3), 537-597.

_, Raymond Fisman, Paolo Pinotti, and Silvia Vannutelli, "Rules, Discretion, and Corruption in Procurement: Evidence from Italian Government Contracting," NBER WP 28209, 2020.

Duflo, Esther, "Richard T. Ely Lecture: The Economist as Plumber," American Economic Review, 2017, 107 (5), 1-26.

_, Michael Greenstone, Rohini Pande, and Nicholas Ryan, "Truth-Telling by Third-Party Auditors and the Response of Polluting Firms: Experimental Evidence from India," Quarterly Journal of Economics, 2013, 128 (4), 1499-1545.

_ , _ , _, and _, "What Does Reputation Buy? Differentiation in a Market for Third-Party Auditors," American Economic Review: Papers and Proceedings, 2013, 103 (3), 314-19.

_ , _ , , and _ , "The Value of Regulatory Discretion: Estimates from Environmental Inspections in India," Econometrica, 2018, 86 (6), 2123-2160.

Engel, Eduardo, Felipe Jordán, Tomás Rau, and Andrea Repetto, "Supreme Audit Institutions and Deterrence: Experimental Evidence from Chile," Economic Behavior $\&$ Organization, 2017, pp. 1-23.

Feir, Donna, Thomas Lemieux, and Vadim Marmer, "Weak Identification in Fuzzy Regression Discontinuity Designs," Journal of Business 8 Economic Statistics, 2016, 34 (2), 185-196.

Ferraz, Claudio and Frederico Finan, "Exposing Corrupt Politicians: The Effects of Brazil's Publicly Released Audits on Electoral Outcomes," Quarterly Journal of Economics, 2008. 
_, _, and Dimitri Szerman, "Procuring Firm Growth: The Effects of Government Purchases on Firm Dynamics," WP, 2021.

Gonzalez-Lira, Andres and Ahmed Mushfiq Mobarak, "Slippery Fish: Enforcing Regulation under Subversive Adaptation," IZA DP 12179, 2019.

Governmental Auditing Standards and Title 2 U.S. Code of Federal Regulations, "2 CFR PART 200, APPENDIX XI, Compliance Supplement," 2020.

Hahn, Jinyong, Petra Todd, and Wilbert Van der Klaauw, "Identification and Estimation of Treatment Effects with a Regression-Discontinuity Design," Econometrica, 2001, 69.

Hastings, Justine S, Christopher A Neilson, and Seth D Zimmerman, "Are Some Degrees Worth More than Others? Evidence from College Admission Cutoffs in Chile," NBER WP 19241, 2014.

Hjort, Jonas, Vinayak Iyer, and Golvine de Rochambeau, "Informational Barriers to Market Access: Experimental Evidence from Liberian Firms," CEPR DP 15219, 2021.

Imbens, Guido and Karthik Kalyanaraman, "Optimal Bandwidth Choice for the Regression Discontinuity Estimator," Review of Economic Studies, 2012, 79 (3), 933-959.

- and Thomas Lemieux, "Regression Discontinuity Designs: A Guide to Practice," Journal of Econometrics, 2008, 142 (2), 615-635.

INTOSAI, "The Auditing Function of Supreme Audit Institutions: A Systematic Mapping of the Auditing Assignments of 37 Selected Supreme Audit Institutions across the Regions of INTOSAI," 2010.

Kahn, Charles M., Emilson C. D. Silva, and James P. Ziliak, "Performance-Based Wages in Tax Collection: The Brazilian Tax Collection Reform and its Effects," Economic Journal, 2001, 111 (468), 188-205.

Kaufmann, Katja Maria, Matthias Messner, and Alex Solis, "Returns to Elite Higher Education in the Marriage Market: Evidence from Chile," IGIER WP 489, 2013.

Khan, Adnan Q., Asim I. Khwaja, and Benjamin A. Olken, "Tax Farming Redux: Experimental Evidence on Performance Pay for Tax Collectors," Quarterly Journal of Economics, 2016, 131 (1), 219-271.

Kleven, Henrik, Martin Knudsen, Claus Kreiner, Søren Pedersen, and Emmanuel Saez, "Unwilling or Unable to Cheat? Evidence From a Tax Audit Experiment in Denmark," Econometrica, 2011, 79 (3), 651-692.

Kovalchuk, Artur, Charles Kenny, and Mallika Snyder, "Examining the Impact of EProcurement in Ukraine," CGD WP 511, 2019.

Lalive, Rafael, Armin Schmutzler, and Christine Zulehner, "Auctions vs Negotiations in Public Procurement: Which Works Better," UZH ECON WP 209, 2015.

Lee, David S. and Thomas Lemieux, "Regression Discontinuity Designs in Economics," Journal of Economic Literature, 2010, 48 (2), 281-355.

Lewis-Faupel, Sean, Yusuf Neggers, Benjamin A. Olken, and Rohini Pande, "Can Electronic Procurement Improve Infrastructure Provision? Evidence from Public Works in India and Indonesia," American Economic Journal: Economic Policy, 2016, 8 (3), 258-83.

Lichand, Guilherme and Gustavo Fernandes, "The Dark Side of the Contract: Do Government Audits Reduce Corruption in the Presence of Displacement by Vendors?," 2019.

McCrary, Justin, "Manipulation of the Running Variable in the Regression Discontinuity Design: A Density Test," Journal of Econometrics, 2008, 142 (2), 698-714.

Minnesota Auditor General Office, "Minnesota Legal Compliance Audit Guide for School Districts," 2018.

Niehaus, Paul and Sandip Sukhtankar, "Corruption Dynamics: The Golden Goose Effect," American Economic Journal: Economic Policy, 2013, 5 (4), 230-269.

OECD, "Chile's Supreme Audit Institution: Enhancing Strategic Agility and Public Trust," 2014. 
_ , "OECD Recommendation of the Council on Public Procurement," 2015.

_ , "Towards Efficient Public Procurement in Colombia: Making the Difference," 2016.

_ , "Global Forum on Competition: Roundtable on Collusion and Corruption in Public Procurement," 2016.

Office of Management and Budget, "2 CFR PART 200, APPENDIX XI, Compliance Supplement," 2018.

Olken, Benjamin A., "Monitoring Corruption: Evidence from a Field Experiment in Indonesia," Journal of Political Economy, 2007, 115 (2), 200-249.

Palguta, Ján and Filip Pertold, "Manipulation of Procurement Contracts: Evidence from the Introduction of Discretionary Thresholds," American Economic Journal: Economic Policy, 2017.

Pomeranz, Dina, "No Taxation without Information: Deterrence and Self-Enforcement in the Value Added Tax," American Economic Review, 2015, 105 (8), 2539-2569.

_ and José Vila-Belda, "Taking State-Capacity Research to the Field: Insights from Collaborations with Tax Authorities," Annual Review of Economics, 2019, 11, 755-781.

Pop-Eleches, Cristian and Miguel Urquiola, "Going to a Better School: Effects and Behavioral Responses," American Economic Review, 2013, 103 (4), 1289-1324.

Robinson, James A. and Jonathan Weigel, "Navigating the Deep: The Political Economy of Public Spending in Haiti," 2018.

Secretaría de la Función Pública de Mexico, "Guía de Auditoría de Adquisiciones, Arrendamientos y Servicios Del Sector Público," 2009.

Simon, Herbert A, "Theories of Bounded Rationality," Decision and Organization, 1972, 1 (1).

Spagnolo, Giancarlo, "Reputation, Competition and Entry in Procurement," International Journal of Industrial Organization, 2012, 30 (3), 291-296.

Sri Lanka Auditor General's Department, "Sri Lanka Auditor General's Department Procurement Audit Manual," 2016.

Stigler, George J., "The Optimum Enforcement of Laws," Journal of Political Economy, 1970.

Szucs, Ferenc, "Discretion and Favoritism in Public Procurement," 2020.

The Contact Committee of the Supreme Audit Institutions of the European Union, Public Procurement Audit, Tribunal de Contas, Portugal, 2018.

Tran, Anh, "Which Regulations Reduce Corruption? Evidence from the Internal Records of a Bribe-Paying Firm," Journal of Development Economics, 2011.

Transparency International, "Corruption Perceptions Index 2012," 2012.

UNSPSC, "UNSPSC Classification," Uniform Code Council, Inc. 2004.

World Bank, "New Procurement Framework and Regulations for Projects After July 1, 2016," 2016.

Yang, Dean, "Can Enforcement Backfire? Crime Displacement in the Context of Customs Reform in the Philippines," The Review of Economics and Statistics, 2008, 90 (1), 1-14.

Zamboni, Yves and Stephan Litschig, "Audit Risk and Rent Extraction: Evidence from a Randomized Evaluation in Brazil," Journal of Development Economics, 2018, 134, 133-149. 
Figure 1:

McCrary Density Test

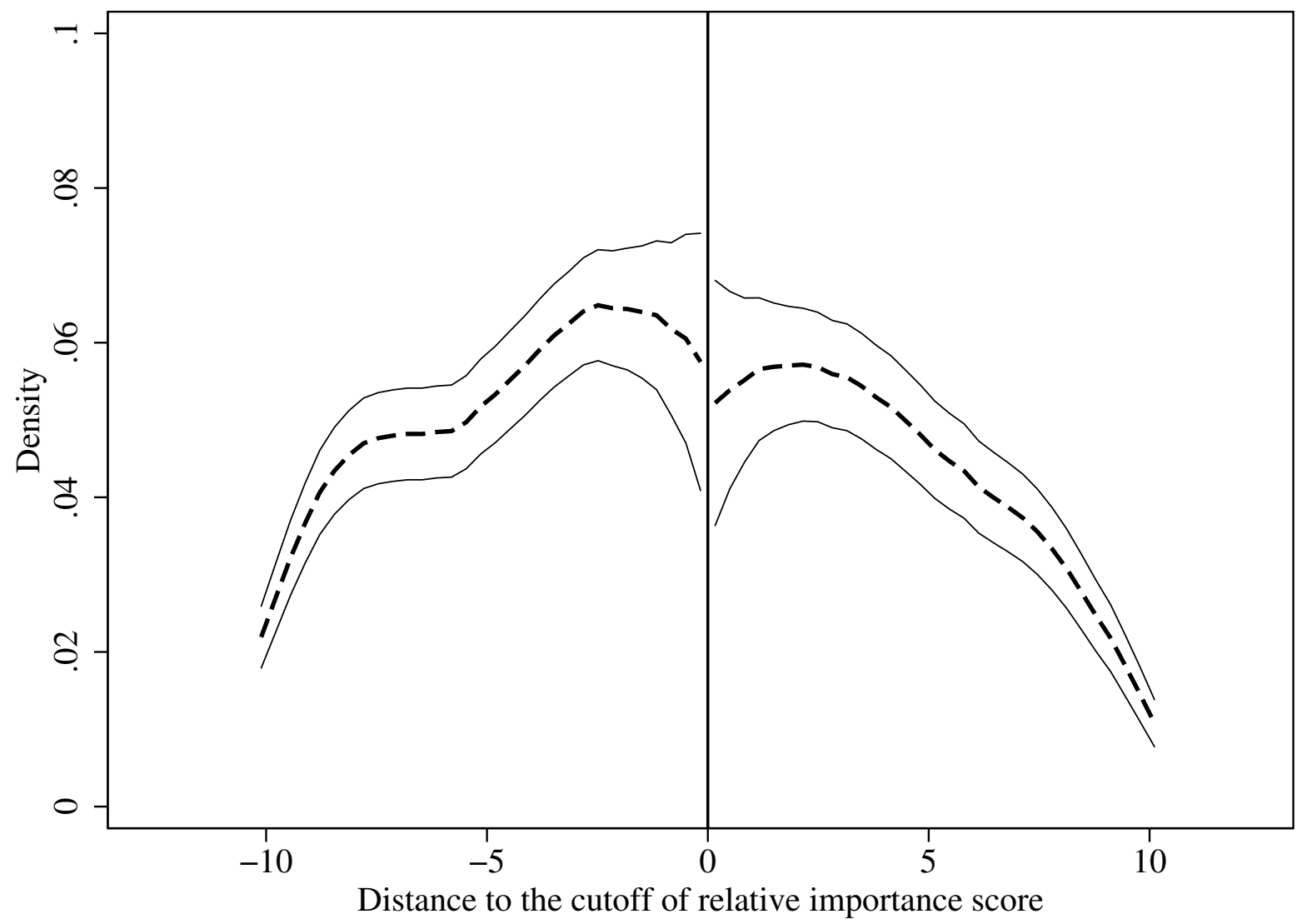

Notes: This figure shows the McCrary density test (McCrary, 2008) to analyze whether there is systematic bunching on one side of the cut-off. The dashed line indicates the density estimate, the solid lines show the $95 \%$ confidence interval. The estimated $\log$ difference in the heights at the cutoff is -0.1 and it has a standard error of 0.2. The analysis includes the pooled sample of entities in 2011-2012 with medium level of risk in the \pm 10 range around the cutoffs of the importance score used in our main analysis. Zero indicates the cutoff at the stratum level. A stratum refers to a cell defined by year and internal unit. 
Figure 2:

Residual Share of Audited Entities (First Stage)

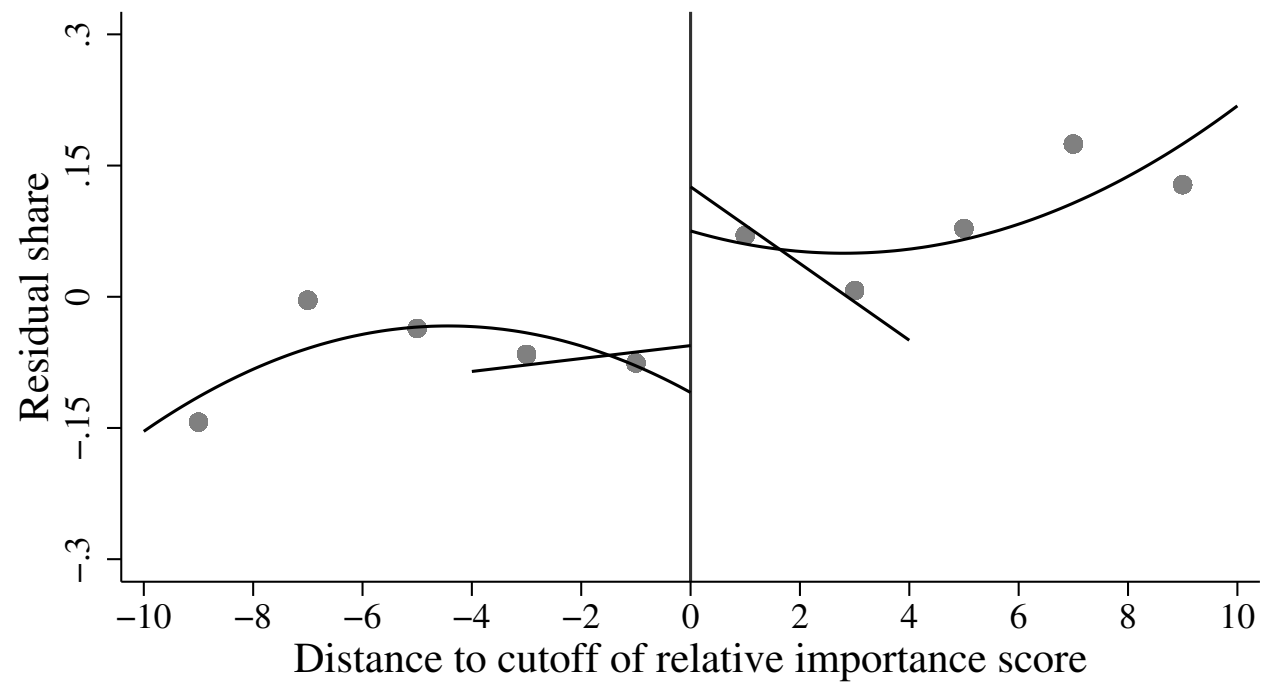

Notes: This figure shows the share of audited entities with medium level of risk in the \pm 10 range of the importance score for the years 2011 and 2012. The dots represent residual audit probabilities averaged within 2-point-wide intervals of the importance score. The residuals are obtained from a regression of the dummy for having been audited in a given year on stratum fixed effects and control variables. Control variables include a dummy for having been audited in the preceding year (audits data are not available for two years earlier), political affiliation, as well as first and second lags of $\log (+1)$ of total amount purchased, and of auction and direct contract shares. Importance scores are normalized by stratum-level cutoff. A stratum refers to a cell defined by year and internal unit. Solid lines show linear and quadratic fits. Appendix Figure A4 shows the same with 1-point-wide intervals. 
Figure 3:

Share of Spending by Purchase Procedure

Panel A: Auctions Share

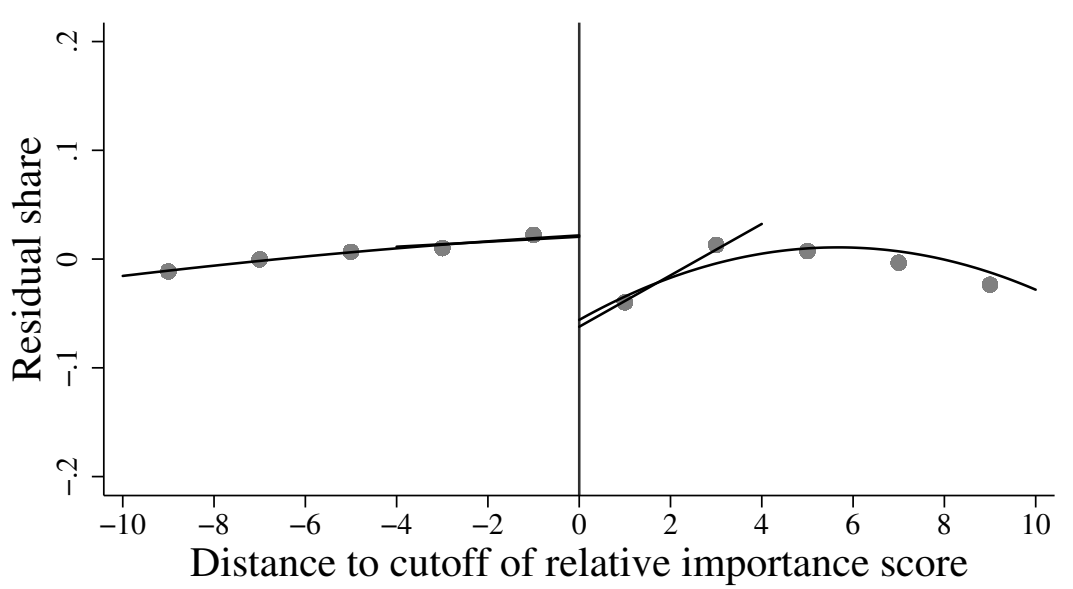

Panel C: Framework Agreement Share

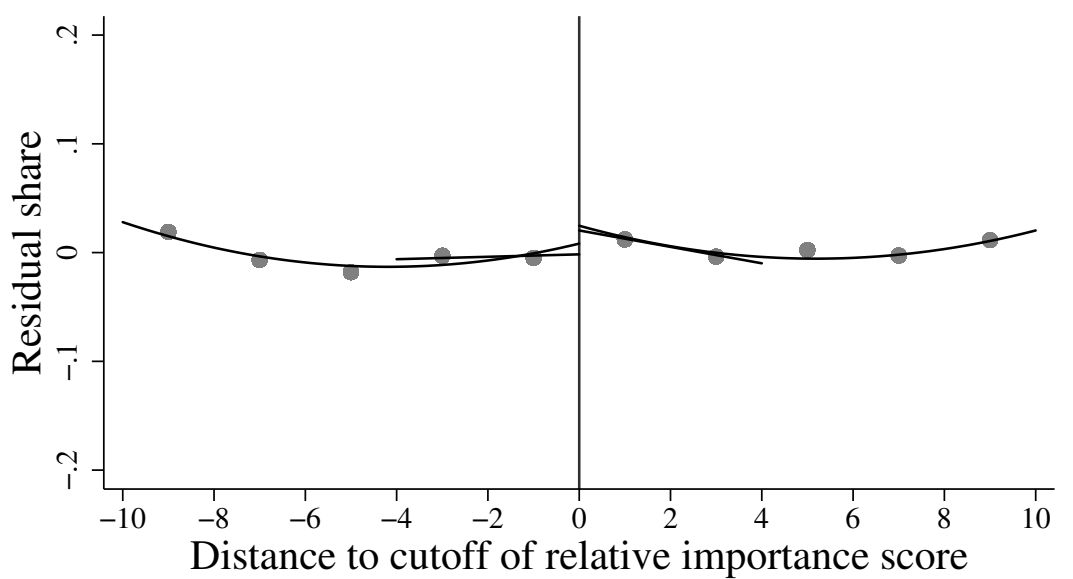

Panel B: Direct Contracting Share

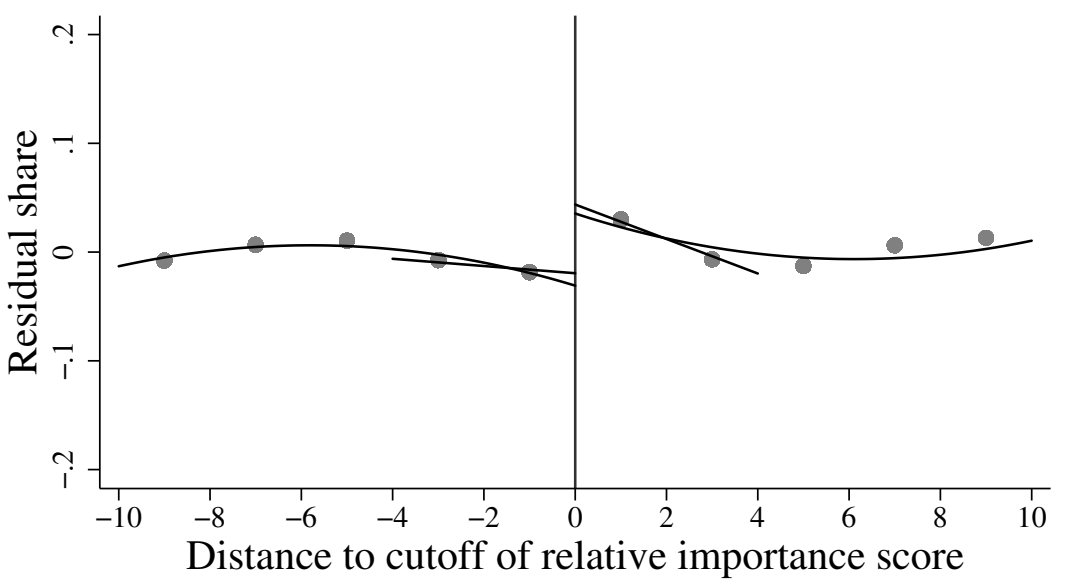

Panel D: Small Purchases Share

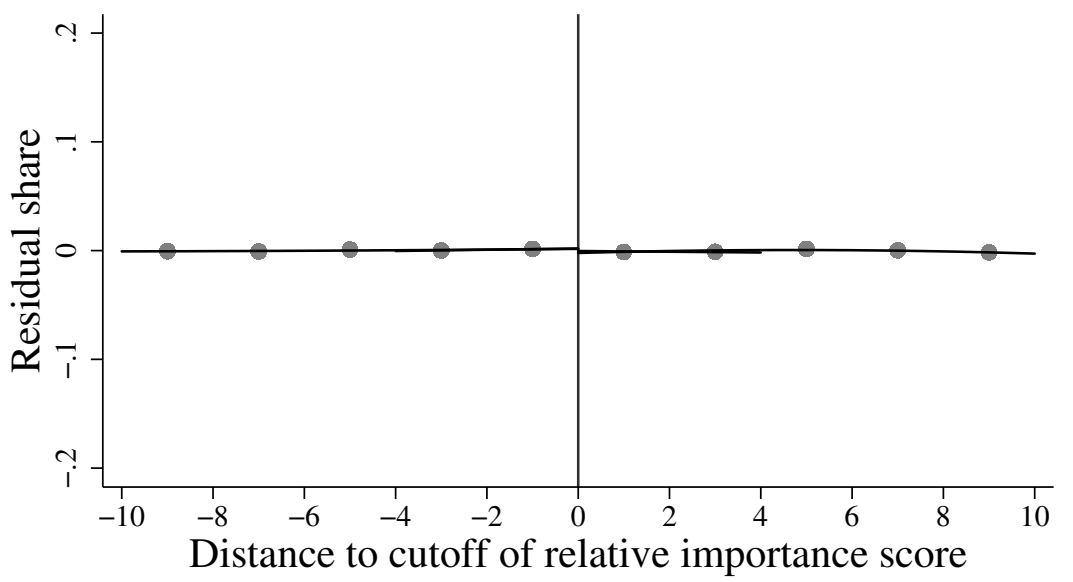

Notes: This figure shows the value of purchases made through auctions (Panel A), direct contracting (Panel B), framework agreement (Panel C) and small purchases (Panel D), as a share of total procurement spending by a given entity with medium level of risk in the \pm 10 range of the importance score threshold for the years 2011 and 2012 . The dots represent residual procedure shares averaged within 2-point-wide intervals of the importance score. The residuals are obtained from a regression of the outcome in a given year on stratum fixed effects and control variables. Control variables include a dummy for having been audited in the preceding year (audits data are not available for two years earlier), political affiliation, as well as first and second lags of log $(+1)$ of total amount purchased, of auction and direct contract shares, and of the outcome variable (where different). The importance score for each entity is normalized by the stratum-level cutoff. A stratum refers to a cell defined by year and internal unit. Solid lines show linear and quadratic fits. Appendix Figure A5 shows the same with 1-point-wide intervals. 
Figure 4: Impacts on Shares of Spending Through Auctions and Direct Contracting Over Time

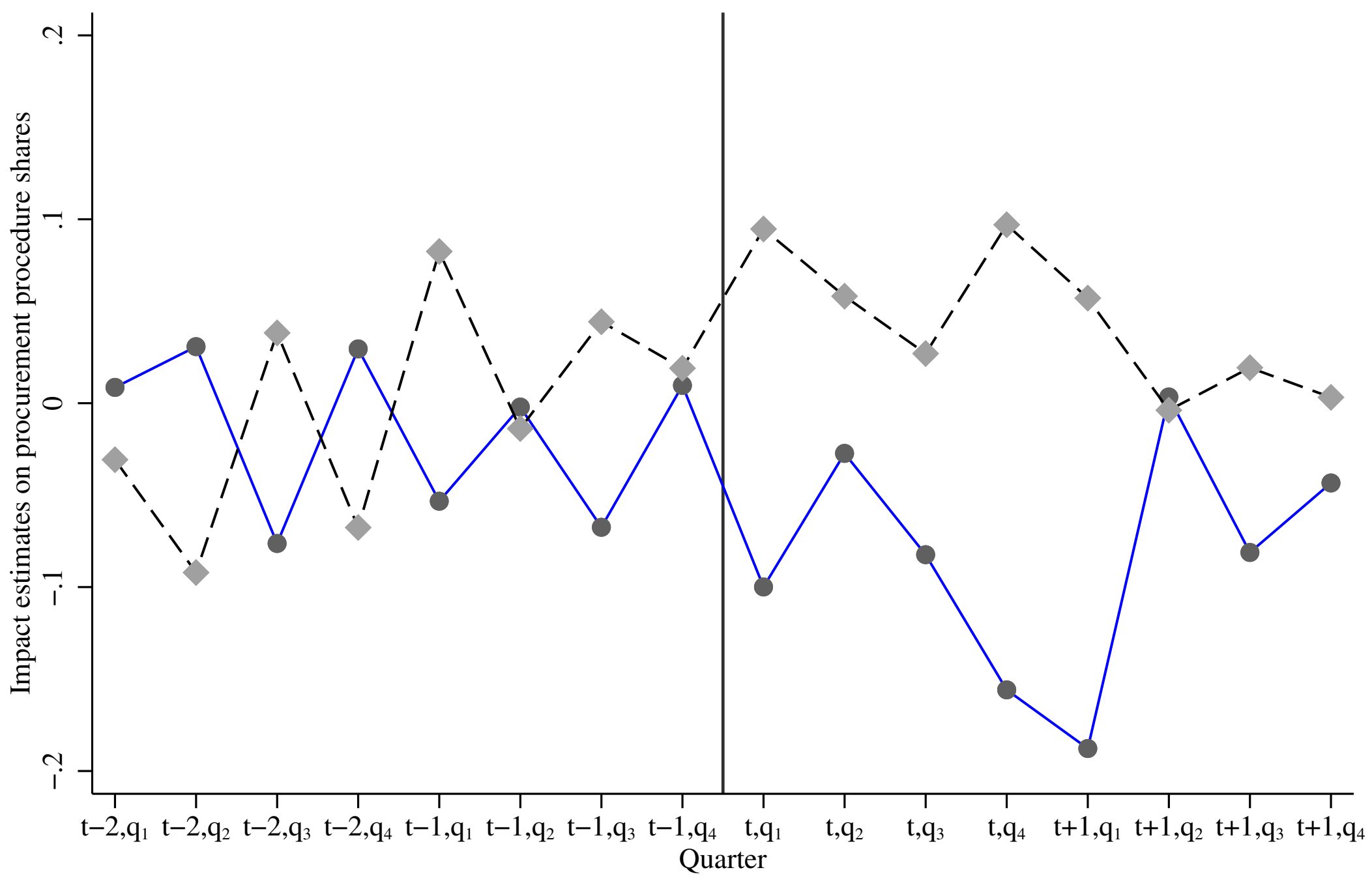

\section{Auction share $\quad-->-$ Direct contracting share}

Notes: This figure shows the evolution of reduced form RDD estimates of impacts on auction and direct contracting shares over time, following Equation (2) on a quarterly basis. Coefficients plotted correspond to the bias-corrected estimates using the MSEoptimal bandwidth. Control variables include a dummy for having been audited in the preceding year (audits data are not available for two years earlier), political affiliation, as well as first and second lags of log $(+1)$ of total amount purchased, and of auction and direct contract shares. Period $\mathrm{t}, \mathrm{q}_{1}$ corresponds to the first quarter of year $t$. 
Figure 5: Additional Audits: Checks and Infractions by Purchase Procedure

Panel A: Checks

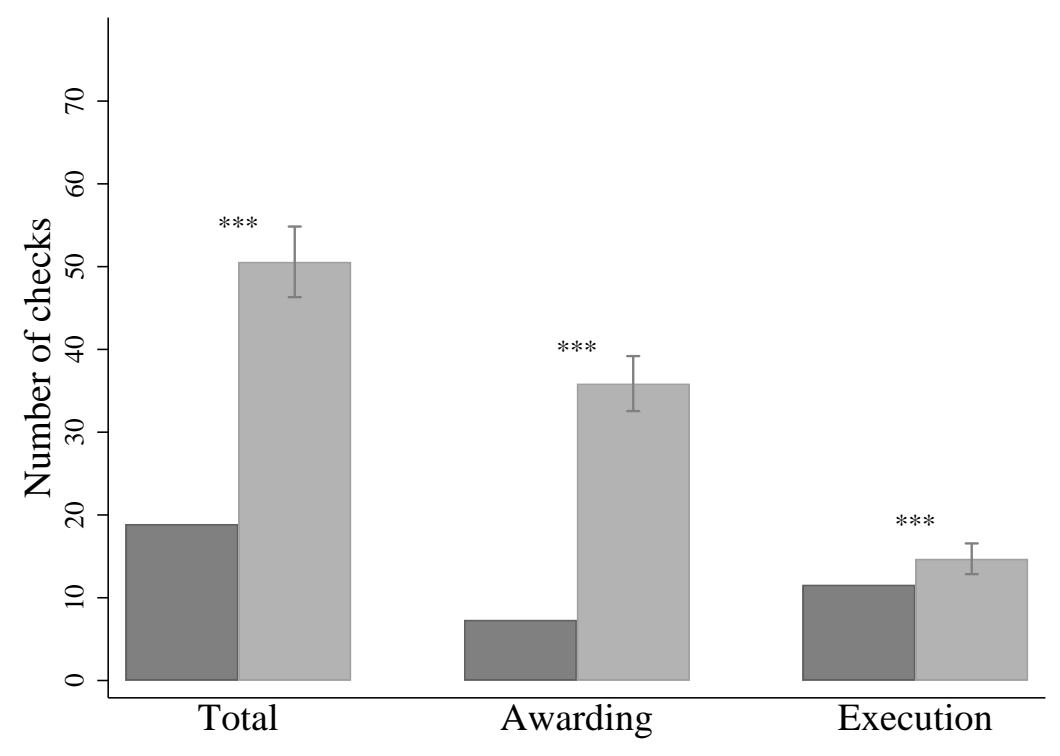

Panel B: Detected Infractions

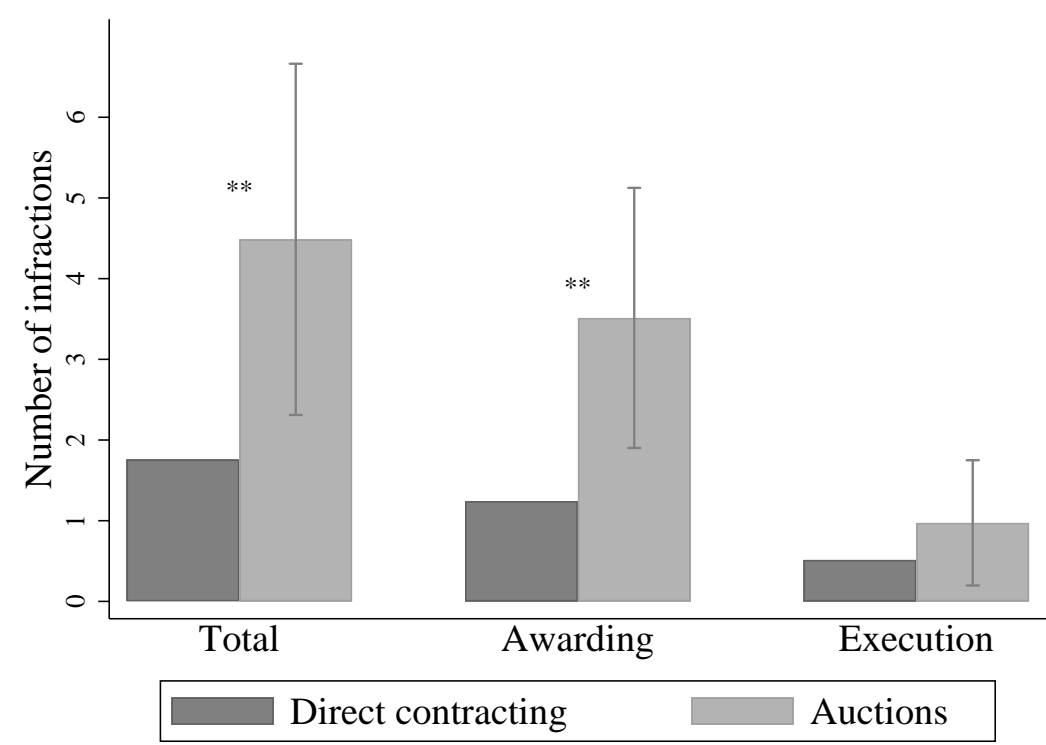

Notes: Panel A shows the number of checks per audited contract and Panel B shows the number of detected infractions. The left-hand set of bars displays the total number, the center bars show the number in the awarding stage, and the right-hand bars show the execution stage. The dark gray bars indicate mean numbers for direct contracts. The light gray bars show expected outcomes for auctions based on OLS regressions of the outcome on an auction dummy and controls for purchase amount, product, month of purchase, month of audit, and internal unit (as in Table A12 Panel B). The 95\% confidence interval is based on the standard error of the difference estimate. Standard errors are clustered at the entity level. Appendix Figure A6 plots the same analysis without controls. 
Table 1:

Summary Statistics

\begin{tabular}{|c|c|c|c|c|c|}
\hline & $(1)$ & $(2)$ & $(3)$ & $(4)$ & $(5)$ \\
\hline \multirow[t]{2}{*}{ Purchase Procurement Procedure } & $\begin{array}{l}\text { Amount in } \\
\text { Millions of USD }\end{array}$ & $\begin{array}{c}\text { Share of Total } \\
\text { Amount } \\
\text { Purchased }\end{array}$ & $\begin{array}{l}\text { Number of } \\
\text { Purchases }\end{array}$ & $\begin{array}{c}\text { Share of } \\
\text { Purchases }\end{array}$ & $\begin{array}{l}\text { Average Number } \\
\text { of } \\
\text { Bidders/Quotes }\end{array}$ \\
\hline & \multicolumn{5}{|c|}{ Panel A: Full Sample } \\
\hline Auction & 6,597 & $63.92 \%$ & $4,350,037$ & $50.81 \%$ & 13.1 \\
\hline Direct contract & 1,882 & $18.24 \%$ & $1,285,021$ & $15.01 \%$ & 1.4 \\
\hline Framework agreement & 1,803 & $17.47 \%$ & $2,279,560$ & $26.63 \%$ & \\
\hline \multirow[t]{2}{*}{ Small purchases } & 39 & $0.38 \%$ & 646,932 & $7.56 \%$ & \\
\hline & \multicolumn{5}{|c|}{ Panel B: Estimation Sample } \\
\hline Auction & 2,597 & $66.58 \%$ & $1,827,455$ & $52.76 \%$ & 13.0 \\
\hline Direct contract & 675 & $17.30 \%$ & 482,816 & $13.94 \%$ & 1.4 \\
\hline Framework agreement & 613 & $15.72 \%$ & 889,745 & $25.69 \%$ & \\
\hline Small purchases & 16 & $0.40 \%$ & 263,575 & $7.61 \%$ & \\
\hline
\end{tabular}

Notes: The full sample consists of all 2,720 procuring public entity-years in 2011 and 2012 . The estimation sample consists of the 1,002 public entity-years with medium risk whose normalized importance scores for the year in question was within the \pm 10 range of the cutoff. Column (5) shows the average number of bidders in auctions and the average number of required quotes for direct contracting. 
Table 2:

Balance Test

\begin{tabular}{|c|c|c|c|c|c|c|}
\hline & $(1)$ & $(2)$ & $(3)$ & $(4)$ & $(5)$ & (6) \\
\hline & $\begin{array}{c}\text { Comparison } \\
\text { mean } \\
( \pm 4)\end{array}$ & $\begin{array}{l}\text { Discontinuity } \\
\text { estimate } \\
\text { (linear) } \\
( \pm 4)\end{array}$ & $\begin{array}{l}\text { Discontinuity } \\
\text { estimate } \\
\text { (linear) } \\
( \pm 4)\end{array}$ & $\begin{array}{l}\text { Comparison } \\
\text { mean } \\
( \pm 10)\end{array}$ & $\begin{array}{l}\text { Discontinuity } \\
\text { estimate } \\
\text { (quadratic) } \\
( \pm 10)\end{array}$ & $\begin{array}{l}\text { Discontinuity } \\
\text { estimate } \\
\text { (quadratic) } \\
( \pm 10)\end{array}$ \\
\hline Auctions share, $\underline{\mathrm{t}-1}$ & 0.656 & $\begin{array}{l}-0.007 \\
(0.035)\end{array}$ & $\begin{array}{l}-0.026 \\
(0.026)\end{array}$ & 0.695 & $\begin{array}{l}-0.035 \\
(0.035)\end{array}$ & $\begin{array}{c}-0.048^{*} \\
(0.026)\end{array}$ \\
\hline Direct contracting share, $\underline{\mathrm{t}-1}$ & 0.146 & $\begin{array}{c}0.050 \\
(0.032)\end{array}$ & $\begin{array}{c}0.023 \\
(0.026)\end{array}$ & 0.123 & $\begin{array}{c}0.050 \\
(0.033)\end{array}$ & $\begin{array}{c}0.036 \\
(0.026)\end{array}$ \\
\hline Framework agreement share, $\underline{\mathrm{t}-1}$ & 0.183 & $\begin{array}{l}-0.044 \\
(0.029)\end{array}$ & $\begin{array}{l}-0.004 \\
(0.021)\end{array}$ & 0.168 & $\begin{array}{l}-0.021 \\
(0.030)\end{array}$ & $\begin{array}{c}0.004 \\
(0.022)\end{array}$ \\
\hline Log $(+1)$ of total amount purchased, t-1 & 13.331 & $\begin{array}{c}0.317 \\
(0.322)\end{array}$ & $\begin{array}{l}-0.123 \\
(0.128)\end{array}$ & 13.244 & $\begin{array}{c}0.096 \\
(0.311)\end{array}$ & $\begin{array}{l}-0.100 \\
(0.130)\end{array}$ \\
\hline Auctions share, $\underline{\mathrm{t}-2}$ & 0.694 & $\begin{array}{c}0.009 \\
(0.041)\end{array}$ & $\begin{array}{l}-0.032 \\
(0.036)\end{array}$ & 0.731 & $\begin{array}{l}-0.005 \\
(0.039)\end{array}$ & $\begin{array}{l}-0.056 \\
(0.036)\end{array}$ \\
\hline Direct contracting share, $\underline{\mathrm{t}-2}$ & 0.128 & $\begin{array}{c}0.020 \\
(0.028)\end{array}$ & $\begin{array}{c}0.004 \\
(0.030)\end{array}$ & 0.111 & $\begin{array}{c}0.019 \\
(0.032)\end{array}$ & $\begin{array}{c}0.025 \\
(0.029)\end{array}$ \\
\hline Framework agreement share, $\underline{\mathrm{t}-2}$ & 0.155 & $\begin{array}{l}-0.028 \\
(0.029)\end{array}$ & $\begin{array}{c}0.021 \\
(0.026)\end{array}$ & 0.138 & $\begin{array}{l}-0.014 \\
(0.028)\end{array}$ & $\begin{array}{c}0.024 \\
(0.024)\end{array}$ \\
\hline Log $(+1)$ of total amount purchased, t $\underline{\mathrm{t}-2}$ & 13.176 & $\begin{array}{c}0.233 \\
(0.349)\end{array}$ & $\begin{array}{l}-0.001 \\
(0.178)\end{array}$ & 13.079 & $\begin{array}{l}-0.001 \\
(0.339)\end{array}$ & $\begin{array}{l}-0.096 \\
(0.140)\end{array}$ \\
\hline Audited, t-1 & 0.187 & $\begin{array}{c}0.042 \\
(0.069)\end{array}$ & $\begin{array}{c}0.002 \\
(0.055)\end{array}$ & 0.163 & $\begin{array}{c}0.085 \\
(0.074)\end{array}$ & $\begin{array}{c}0.067 \\
(0.069)\end{array}$ \\
\hline Right-wing & 0.671 & $\begin{array}{l}-0.047 \\
(0.099)\end{array}$ & $\begin{array}{l}0.107^{*} \\
(0.056)\end{array}$ & 0.695 & $\begin{array}{l}-0.092 \\
(0.111)\end{array}$ & $\begin{array}{l}-0.003 \\
(0.058)\end{array}$ \\
\hline Independent & 0.108 & $\begin{array}{c}0.069 \\
(0.052)\end{array}$ & $\begin{array}{c}0.011 \\
(0.042)\end{array}$ & 0.103 & $\begin{array}{c}0.071 \\
(0.057)\end{array}$ & $\begin{array}{c}0.049 \\
(0.043)\end{array}$ \\
\hline $\begin{array}{l}\text { F-statistic } \\
\text { [p-value] }\end{array}$ & & $\begin{array}{c}0.70 \\
{[0.744]}\end{array}$ & $\begin{array}{c}1.20 \\
{[0.278]}\end{array}$ & & $\begin{array}{c}0.84 \\
{[0.596]}\end{array}$ & $\begin{array}{c}1.50 \\
{[0.124]}\end{array}$ \\
\hline
\end{tabular}

Notes: This table tests whether there is a systematic imbalance of covariates at the cutoffs used in all our main analyses. It shows results from running RDD analyses for each covariate as the outcome, as in Equation (2). Each coefficient in Columns (2)-(3) and (5)-(6) shows the result of a separate regression to test for discontinuity. Columns (2) and (3) show linear estimates in the \pm 4 range, without and with stratum fixed effects, respectively. Columns (5) and (6) display the corresponding quadratic estimates. The F-statistic is from a test of the joint hypotheses that all discontinuities in a given column are zero. Columns (1) and (4) show comparison means, i.e., estimated means to the left of the cutoff in the \pm 4 and \pm 10 range, respectively. Each observation is an entity-year. Standard errors are clustered at the stratum level. A stratum refers to a cell defined by year and internal unit. ${ }^{* * *} \mathrm{p}<0.01,{ }^{* *} \mathrm{p}<0.05,{ }^{*} \mathrm{p}<0.1$ 
Table 3:

First Stage: Impact on Share of Audited Entities

(3)

(4)

(5)

(6)

(7)

Audit Probability

\begin{tabular}{|c|c|c|c|c|c|c|c|c|}
\hline $1\{$ Relative importance $\geq$ cutoff $\}$ & $\begin{array}{c}0.296^{* * *} \\
(0.074)\end{array}$ & $\begin{array}{l}0.203^{* *} \\
(0.078)\end{array}$ & $\begin{array}{l}0.181^{* *} \\
(0.069)\end{array}$ & $\begin{array}{c}0.299^{* * *} \\
(0.088)\end{array}$ & $\begin{array}{l}0.220^{* *} \\
(0.087)\end{array}$ & $\begin{array}{l}0.193^{* *} \\
(0.084)\end{array}$ & $\begin{array}{l}0.158^{* *} \\
(0.067)\end{array}$ & $\begin{array}{l}0.183^{* *} \\
(0.076)\end{array}$ \\
\hline Bandwidth & \pm 4 & \pm 4 & \pm 4 & \pm 10 & \pm 10 & \pm 10 & \pm 6.53 & \pm 6.53 \\
\hline Observations & 482 & 482 & 477 & 1,002 & 1,002 & 992 & 717 & 717 \\
\hline R-squared & 0.035 & 0.311 & 0.396 & 0.050 & 0.276 & 0.354 & 0.403 & 0.403 \\
\hline Comparison mean & 0.136 & 0.136 & 0.136 & 0.071 & 0.071 & 0.071 & 0.118 & 0.118 \\
\hline Local polynomial & Linear & Linear & Linear & Quadr. & Quadr. & Quadr. & Linear & Linear \\
\hline Stratum fixed effects & No & Yes & Yes & No & Yes & Yes & Yes & Yes \\
\hline Additional controls & No & No & Yes & No & No & Yes & Yes & Yes \\
\hline
\end{tabular}

Notes: First stage RDD estimates following the specification of Equation (1). Columns (1) to (3) show estimations for the \pm 4 bandwidth and Columns (4) to (6) for the \pm 10 bandwidth with varying number of control variables. Columns (7) and (8) employ the mean-squared-erroroptimal bandwidth following Imbens and Kalyanaraman (2012). Column (8) in addition reports bias-corrected estimates and robust standard errors following Calonico et al. (2014). Each observation is an entity-year. Control variables include a dummy for having been audited in the preceding year (audits data are not available for two years earlier), political affiliation, as well as first and second lags of log $(+1)$ of total amount purchased, and of auction and direct contract shares. Standard errors are clustered at the level of the strata. A stratum refers to a cell defined by year and internal unit. ${ }^{* * *} \mathrm{p}<0.01,{ }^{* *} \mathrm{p}<0.05,{ }^{*} \mathrm{p}<0.1$ 
Table 4:

Impact on Share of Spending Through Auctions and Direct Contracting

\begin{tabular}{|c|c|c|c|c|c|c|c|c|}
\hline & (1) & $(2)$ & $(3)$ & $(4)$ & $(5)$ & $(6)$ & $(7)$ & $(8)$ \\
\hline & \multicolumn{8}{|c|}{ Panel A: Auctions } \\
\hline $1\{$ Relative importance $\geq$ cutoff $\}$ & $\begin{array}{l}-0.065 \\
(0.045)\end{array}$ & $\begin{array}{c}-0.073^{*} \\
(0.043)\end{array}$ & $\begin{array}{c}-0.069^{* *} \\
(0.032)\end{array}$ & $\begin{array}{c}-0.081^{* *} \\
(0.038)\end{array}$ & $\begin{array}{c}-0.126^{* * *} \\
(0.036)\end{array}$ & $\begin{array}{l}-0.085^{* * *} \\
(0.027)\end{array}$ & $\begin{array}{c}-0.079^{* * *} \\
(0.030)\end{array}$ & $\begin{array}{c}-0.089^{* *} \\
(0.036)\end{array}$ \\
\hline Bandwidth & \pm 4 & \pm 4 & \pm 4 & \pm 10 & \pm 10 & \pm 10 & \pm 5.19 & \pm 5.19 \\
\hline Observations & 482 & 482 & 477 & 1,002 & 1,002 & 992 & 604 & 604 \\
\hline R-squared & 0.030 & 0.350 & 0.614 & 0.016 & 0.257 & 0.578 & 0.573 & 0.573 \\
\hline \multirow[t]{2}{*}{ Comparison mean } & 0.637 & 0.637 & 0.637 & 0.665 & 0.665 & 0.665 & 0.666 & 0.666 \\
\hline & \multicolumn{8}{|c|}{ Panel B: Direct Contracting } \\
\hline $1\{$ Relative importance $\geq$ cutoff $\}$ & $\begin{array}{c}0.087^{* * *} \\
(0.032)\end{array}$ & $\begin{array}{l}0.079^{* *} \\
(0.037)\end{array}$ & $\begin{array}{l}0.061^{* *} \\
(0.028)\end{array}$ & $\begin{array}{c}0.097^{* * *} \\
(0.032)\end{array}$ & $\begin{array}{c}0.109^{* * *} \\
(0.038)\end{array}$ & $\begin{array}{c}0.073^{* * *} \\
(0.025)\end{array}$ & $\begin{array}{c}0.069^{* * *} \\
(0.024)\end{array}$ & $\begin{array}{c}0.077^{* * *} \\
(0.028)\end{array}$ \\
\hline Bandwidth & \pm 4 & \pm 4 & \pm 4 & \pm 10 & \pm 10 & \pm 10 & \pm 5.05 & \pm 5.05 \\
\hline Observations & 482 & 482 & 477 & 1,002 & 1,002 & 992 & 593 & 593 \\
\hline R-squared & 0.043 & 0.221 & 0.535 & 0.017 & 0.114 & 0.508 & 0.498 & 0.498 \\
\hline Comparison mean & 0.136 & 0.136 & 0.136 & 0.110 & 0.110 & 0.110 & 0.125 & 0.125 \\
\hline Local polynomial & Linear & Linear & Linear & Quadr. & Quadr. & Quadr. & Linear & Linear \\
\hline Stratum fixed effects & No & Yes & Yes & No & Yes & Yes & Yes & Yes \\
\hline Additional controls & No & No & Yes & No & No & Yes & Yes & Yes \\
\hline
\end{tabular}

Notes: Reduced form RDD estimates following the specification of Equation (2). Columns (1) to (3) show estimations for the \pm 4 bandwidth and Columns (4) to (6) for the \pm 10 bandwidth with varying number of control variables. Columns (7) and (8) employ the mean-squared-erroroptimal bandwidth following Imbens and Kalyanaraman (2012). Column (8) in addition reports bias-corrected estimates and robust standard errors following Calonico, Cattaneo and Titiunik (2014). Each observation is an entity-year. Control variables include a dummy for having been audited in the preceding year (audits data are not available for two years earlier), political affiliation, as well as first and second lags of $\log (+1)$ of total amount purchased, and of auction and direct contract shares. Standard errors are clustered at the stratum level. A stratum refers to a cell defined by year and internal unit. ${ }^{* * *} \mathrm{p}<0.01,{ }^{* *} \mathrm{p}<0.05,{ }^{*} \mathrm{p}<0.1$ 
Table 5:

Impact on Product Level Share of Spending Through Auctions and Direct Contracting

\begin{tabular}{lcccc}
\hline \hline & $(1)$ & $(2)$ & $(3)$ & $(4)$ \\
& & & \\
& & Panel A: Auctions & \\
& & & \\
1\{Relative importance $\geq$ cutoff $\}$ & $-0.060^{* *}$ & $-0.060^{* *}$ & $-0.067^{* *}$ & $-0.076^{* *}$ \\
& $(0.024)$ & $(0.025)$ & $(0.028)$ & $(0.033)$ \\
Bandwidth & \pm 4 & \pm 10 & \pm 4.83 & \pm 4.83 \\
Observations & 189,771 & 387,337 & 229,585 & 229,585 \\
R-squared & 0.464 & 0.451 & 0.462 & 0.462 \\
Comparison mean & 0.614 & 0.651 & 0.627 & 0.627 \\
& & & & \\
& & Panel B: Direct Contracting & \\
1\{Relative importance $\geq$ cutoff $\}$ & $0.057^{* *}$ & $0.056^{* *}$ & $0.056^{* *}$ & $0.064^{* *}$ \\
& $(0.022)$ & $(0.023)$ & $(0.025)$ & $(0.029)$ \\
Bandwidth & \pm 4 & \pm 10 & \pm 5.04 & \pm 5.04 \\
Observations & 189,771 & 387,337 & 239,492 & 239,492 \\
R-squared & 0.328 & 0.294 & 0.313 & 0.313 \\
Comparison mean & 0.151 & 0.117 & 0.141 & 0.141 \\
\hline Local polynomial & Linear & Quadr. & Linear & Linear \\
Stratum fixed effects & Yes & Yes & Yes & Yes \\
Additional controls & Yes & Yes & Yes & Yes \\
8-digit product fixed effects & Yes & Yes & Yes & Yes \\
\hline \hline
\end{tabular}

Notes: Reduced form RDD estimates following the specification of Equation (2). The dependent variable is the share of spending through auctions/direct contracts, respectively, out of total spending on a given product by a given entity. Column (1) shows estimations for the \pm 4 bandwidth and column (2) for the \pm 10 bandwidth. Columns (3) and (4) employ the mean-squared-error-optimal bandwidth following Imbens and Kalyanaraman (2012). Column (4) in addition reports bias-corrected estimates and robust standard errors following Calonico, Cattaneo and Titiunik (2014). Control variables include a dummy for having been audited in the preceding year (audits data are not available for two years), political affiliation, as well as first and second lags of $\log (+1)$ of total amount purchased, and of auction and direct contract shares. Regressions are weighted using entity product shares. Standard errors are clustered at the stratum level. A stratum refers to a cell defined by year and internal unit. $* * * \mathrm{p}<0.01$, ${ }^{*} \mathrm{p}<<0.05,{ }^{*} \mathrm{p}<0.1$ 
Table 6:

Probability That the Supplier Is New, Large or From Out-of-Region

\begin{tabular}{|c|c|c|c|c|}
\hline & (1) & $(2)$ & $(3)$ & $(4)$ \\
\hline & \multicolumn{4}{|c|}{ Panel A: New Supplier } \\
\hline $1\{$ Relative importance $\geq$ cutoff $\}$ & $\begin{array}{c}-0.043^{* *} \\
(0.017)\end{array}$ & $\begin{array}{c}-0.046^{* * *} \\
(0.017)\end{array}$ & $\begin{array}{c}-0.024^{*} \\
(0.014)\end{array}$ & $\begin{array}{c}-0.026 \\
(0.017)\end{array}$ \\
\hline Bandwidth & \pm 4 & \pm 10 & \pm 5.45 & \pm 5.45 \\
\hline Observations & $1,141,996$ & $2,442,604$ & $1,556,309$ & $1,556,309$ \\
\hline R-squared & 0.210 & 0.179 & 0.195 & 0.195 \\
\hline \multirow[t]{2}{*}{ Comparison mean } & 0.163 & 0.172 & 0.172 & 0.172 \\
\hline & \multicolumn{4}{|c|}{ Panel B: Large Supplier } \\
\hline $1\{$ Relative importance $\geq$ cutoff $\}$ & $\begin{array}{c}-0.048^{* *} \\
(0.019)\end{array}$ & $\begin{array}{c}-0.060^{* * *} \\
(0.017)\end{array}$ & $\begin{array}{c}-0.065^{* * *} \\
(0.021)\end{array}$ & $\begin{array}{c}-0.072^{* * *} \\
(0.023)\end{array}$ \\
\hline Bandwidth & \pm 4 & \pm 10 & \pm 3.59 & \pm 3.59 \\
\hline Observations & $1,141,996$ & $2,442,604$ & $1,017,045$ & $1,017,045$ \\
\hline R-squared & 0.383 & 0.364 & 0.393 & 0.393 \\
\hline \multirow[t]{2}{*}{ Comparison mean } & 0.308 & 0.299 & 0.303 & 0.303 \\
\hline & \multicolumn{4}{|c|}{ Panel C: Out of Region } \\
\hline $1\{$ Relative importance $\geq$ cutoff $\}$ & $\begin{array}{c}-0.036^{*} \\
(0.020)\end{array}$ & $\begin{array}{c}-0.034^{*} \\
(0.017)\end{array}$ & $\begin{array}{c}-0.055^{* *} \\
(0.027)\end{array}$ & $\begin{array}{c}-0.065^{* *} \\
(0.031)\end{array}$ \\
\hline Bandwidth & \pm 4 & \pm 10 & \pm 2.99 & \pm 2.99 \\
\hline Observations & 974,540 & $2,093,256$ & 703,570 & 703,570 \\
\hline R-squared & 0.511 & 0.496 & 0.529 & 0.529 \\
\hline Comparison mean & 0.431 & 0.445 & 0.467 & 0.467 \\
\hline Local polynomial & Linear & Quadratic & Linear & Linear \\
\hline Stratum fixed effects & Yes & Yes & Yes & Yes \\
\hline Additional controls & Yes & Yes & Yes & Yes \\
\hline
\end{tabular}

Notes: Reduced form RDD estimates following the specification of Equation (2). Each observation corresponds to a purchase. Results show impacts on the probability that the supplier has not sold to this entity in the preceding four years (Panel A), is a large firm (Panel B), or is from another region (Panel C). Panel $\mathrm{C}$ excludes procuring entities in the Metropolitan Region. Column (1) shows estimation for the \pm 4 bandwidth and Column (2) for the \pm 10 bandwidth. Columns (3) and (4) employ the mean-squared-error-optimal bandwidth following Imbens and Kalyanaraman (2012). Column (4) in addition reports bias-corrected estimates and robust standard errors following Calonico, Cattaneo and Titiunik (2014). Control variables include a dummy for having been audited in the preceding year (audits data are not available for two years earlier), political affiliation, first and second lags of $\log (+1)$ of total amount purchased and of auction and direct contract shares, as well as month and product-unit fixed effects. Standard errors are clustered at the stratum level. A stratum refers to a cell defined by year and internal unit. ${ }^{* * *} \mathrm{p}<0.01$, ${ }^{* *} \mathrm{p}<0.05,{ }^{*} \mathrm{p}<0.1$ 
Table 7:

Impact on the Log of Unit Prices

\begin{tabular}{lcccc}
\hline \hline & $(1)$ & $(2)$ & $(3)$ & $(4)$ \\
1\{Relative importance $\geq$ cutoff\} & 0.113 & $0.148^{*}$ & $0.101^{* *}$ & $0.137^{* *}$ \\
& $(0.101)$ & $(0.084)$ & $(0.048)$ & $(0.063)$ \\
Bandwidth & \pm 4 & \pm 10 & \pm 4.27 & \pm 4.27 \\
Observations & 22,066 & 44,612 & 24,101 & 24,101 \\
R-squared & 0.800 & 0.813 & 0.809 & 0.809 \\
Comparison mean & 0.325 & 0.387 & 0.373 & 0.373 \\
\hline Local polynomial & Linear & Quadratic & Linear & Linear \\
Stratum fixed effects & Yes & Yes & Yes & Yes \\
Additional controls & Yes & Yes & Yes & Yes \\
\hline \hline
\end{tabular}

Notes: Reduced form RDD estimates following the specification of Equation (2). Each observation corresponds to a purchase. Sample includes products with clear and comparable units and a sizeable shift in purchase procedure. Column (1) shows estimation for the \pm 4 bandwidth and Column (2) for the \pm 10 bandwidth. Columns (3) and (4) employ the mean-squared-error-optimal bandwidth following Imbens and Kalyanaraman (2012). Column (4) in addition reports biascorrected estimates and robust standard errors following Calonico, Cattaneo and Titiunik (2014). Control variables include a dummy for having been audited in the preceding year (audits data are not available for two years earlier), political affiliation, first and second lags of $\log (+1)$ of total amount purchased and of auction and direct contract shares, as well as month and product-unit fixed effects. Standard errors are clustered at the stratum level. A stratum refers to a cell defined by year, internal unit and type of entity. ${ }^{* * *} \mathrm{p}<0.01,{ }^{* *} \mathrm{p}<0.05,{ }^{*} \mathrm{p}<0.1$ 